\title{
Noncoding RNAs link metabolic reprogramming to immune microenvironment in cancers
}

\author{
Yiyin Zhang ${ }^{1 \dagger}$, Qijiang Mao ${ }^{1 \dagger}$, Qiming Xia ${ }^{1 \dagger}$, Jiaxi Cheng ${ }^{1}$, Zhengze Huang ${ }^{1}$, Yirun Li ${ }^{1}$, Peng Chen ${ }^{1}$, Jing Yang ${ }^{1}$, \\ Xiaoxiao Fan ${ }^{1,2^{*}}$, Yuelong Liang ${ }^{1 *}$ and Hui Lin ${ }^{1,3^{*}}$
}

\begin{abstract}
Altered metabolic patterns in tumor cells not only meet their own growth requirements but also shape an immunosuppressive microenvironment through multiple mechanisms. Noncoding RNAs constitute approximately $60 \%$ of the transcriptional output of human cells and have been shown to regulate numerous cellular processes under developmental and pathological conditions. Given their extensive action mechanisms based on motif recognition patterns, noncoding RNAs may serve as hinges bridging metabolic activity and immune responses. Indeed, recent studies have shown that microRNAs, long noncoding RNAs and circRNAs are widely involved in tumor metabolic rewiring, immune cell infiltration and function. Hence, we summarized existing knowledge of the role of noncoding RNAs in the remodeling of tumor metabolism and the immune microenvironment, and notably, we established the TIMELnc manual, which is a free and public manual for researchers to identify pivotal IncRNAs that are simultaneously correlated with tumor metabolism and immune cell infiltration based on a bioinformatic approach.
\end{abstract}

Keywords: Noncoding RNAs, Tumor metabolism, Immune microenvironment, TIMELnc manual, Bioinformatic approach

\section{Background}

When confronted with the severe nutritional crisis associated with increased interstitial pressure, destruction of vascular structures and hypoxia in the tumor microenvironment, tumor cells and other immunostromal cells experience conspicuous metabolic reprogramming [1-5]. In recent decades, many studies have deciphered alterations in metabolic profiles within tumor cells, and aberrantly activated metabolic pathways such as glycolysis and glutaminolysis allow tumor cells to sustain a higher

\footnotetext{
*Correspondence: fanxx_gs@zju.edu.cn; yuelongliang@zju.edu.cn; 369369@zju.edu.cn

†Yiyin Zhang, Qijiang Mao and Qiming Xia contributed equally to this work

${ }^{1}$ Department of General Surgery, Sir Run Run Shaw Hospital, School of Medicine, Zhejiang University, Hangzhou 310016, China

Full list of author information is available at the end of the article
}

proliferation rate and resist cell death signals [6-9]. However, altered metabolic patterns in tumor cells not only meet their own growth requirements but also shape an immunosuppressive microenvironment by disturbing the metabolism of other cells in the microenvironment through multiple mechanisms [2, 3]. Tumor-derived metabolites directly reduce the antitumor activity and recruitment of immune cells or indirectly compromise their function by inducing the formation of an acidic microenvironment [10-13]. Interestingly, tumor-derived metabolites were recently shown to enhance the function of suppressive immune cells, which dramatically restrained the cytotoxicity of antitumor immune cells [14]. In addition, reprogrammed metabolic pathways regulate the expression of immune checkpoints, while activated immune checkpoints in turn damage anticancer immunity by inducing metabolic reprogramming in

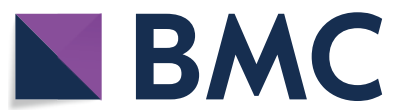

(c) The Author(s) 2021. Open Access This article is licensed under a Creative Commons Attribution 4.0 International License, which permits use, sharing, adaptation, distribution and reproduction in any medium or format, as long as you give appropriate credit to the original author(s) and the source, provide a link to the Creative Commons licence, and indicate if changes were made. The images or other third party material in this article are included in the article's Creative Commons licence, unless indicated otherwise in a credit line to the material. If material is not included in the article's Creative Commons licence and your intended use is not permitted by statutory regulation or exceeds the permitted use, you will need to obtain permission directly from the copyright holder. To view a copy of this licence, visit http://creativecommons.org/licenses/by/4.0/. The Creative Commons Public Domain Dedication waiver (http://creativeco mmons.org/publicdomain/zero/1.0/) applies to the data made available in this article, unless otherwise stated in a credit line to the data. 
T cells [15-17]. Hence, approaches concurrently targeting tumor metabolism serve as a synergetic strategy for immunotherapy.

However, recent studies implied that immunostromal cells also overcome these obstacles by triggering the metabolism-dependent death of tumor cells, which is a mechanism regulating the capability of tumors to plunder nutrients while bypassing the intratumor metabolite pool. For example, CD8+ T cells secrete IFN- $\gamma$ to downregulate the expression of cystine/glutamate antiporter (SLC7A11) on the surface of tumor cells, which dramatically restrains the availability of cysteine, a key factor required for tumor cells to avoid lipid ROS accumulationmediated cell death (ferroptosis) [18]. Moreover, because cysteine is an important nutritional substance for effector $\mathrm{T}$ cells to maintain their normal function, IFN- $\gamma$ mediated SLC7A11 downregulation might be a potent mechanism by which effector $\mathrm{T}$ cells hijack cysteine and improve their antitumor activity [19, 20]. Tumor cells were reported to tame multiple immunostromal cells to fuel their growth. Interestingly, metabolites derived from these tumor-educated cells also compromise antitumor immunity [21-23]. For instance, myeloid-derived suppressive cells (MDSCs) harness the glycolytic byproduct methylglyoxal to suppress effector $\mathrm{T}$ cell function and stimulate tumor development [24].

Nonetheless, the majority of previous studies focused on the direct effect of differentially expressed enzymes on metabolic rewiring and subsequent remodeling of the tumor microenvironment. However, with more awareness of the pathophysiological regulatory mechanism of noncoding RNAs [25-27], small molecules that regulate signaling pathways in cells or intercellularly through multiple pathways, such as binding to DNA, RNA and even proteins, researchers have gradually recognized the potential role of noncoding RNAs in bridging metabolism to anticancer immunity. Compared with the specific maps of interactions between metabolic enzymes and pathways, one noncoding RNA might simultaneously regulate different metabolic pathways via a competing endogenous RNA (ceRNA) network [28, 29], suggesting that some hub noncoding RNAs may exert essential functions at the crossroads of intratumoral metabolism and the immune microenvironment.

In fact, the role of ncRNAs, including miRNAs, lncRNAs and circRNAs, in tumor development has been reported by numerous studies [30,31], and their effects on tumor metabolism have recently received increasing attention [32-36]. Overexpression of some ncRNAs counteracts the antitumor capability of effector $\mathrm{T}$ cells by triggering the aberrant upregulation of immunosuppressive metabolic activity [37, 38]. Stroma-derived metabolites induce an immunosuppressive environment through immune cell polarization and abnormal ncRNA expression to accelerate tumor development [10]. Immunosuppressive metabolic enzymes also destroy the antitumor function of cytotoxic immune cells by altering ncRNA expression [39]. Notably, ncRNAs play an important role in determining the metabolic activity of immune cells, their antitumor function and cell fate [40-42]. In this review, we mainly focused on the pivotal role of ncRNAs in the immunometabolic crosstalk between tumor cells and other cells in the tumor microenvironment, summarizing the current status and future perspectives in this field. Moreover, at the end of this review, we elaborated the Tumor Immuno-MEtabolic-LncRNA (TIMELnc) manual, which identifies potential lncRNAs regulating tumor metabolism and the immune microenvironment. Readers interested in this topic could refer to this manual to identify potential lncRNAs and design their experiments.

\section{Common paradigms for the crosstalk between intratumoral metabolic and immune activity}

We summarized the common crosstalk patterns between intratumoral metabolism and immune activity in this section, which are potentially widely regulated by noncoding RNAs (Fig. 1).

\section{Tumor-derived metabolic products regulate the function of immune cells Lactate}

In the 1920s, Warburg and colleagues reported that tumor cells metabolize approximately ten-fold more glucose to lactate at a particular time than normal cells under aerobic conditions, which is known as the Warburg effect $[43,44]$. In the next few decades, researchers focused on the benefits of the Warburg effect for tumor development, revealing that it not only supports the rapid proliferation of the tumor itself but also regulates the function of immune cells by producing a large amount of lactate $[45,46]$.

Excess lactate directly represses effector $\mathrm{T}$ cell and natural killer (NK) cell function and thereby establishes tumor immunosurveillance [47]. Mechanistically, lactate inhibits RLR signaling by directly binding to the MAVS transmembrane (TM) domain and preventing MAVS aggregation, which further impedes the production of IFN- $\gamma$ by cytotoxic cells [13]. In addition, lactate upregulates the expression of PD-L1 on the tumor cell surface by activating the transcription factor TEAD and its coactivator TAZ [48]; then, elevated PD-L1 expression increases the number of exhausted $\mathrm{T}$ cells in the tumor microenvironment through its interaction with PD-1 [49, 50]. 


\section{Damage the function of anti-tumor cells}

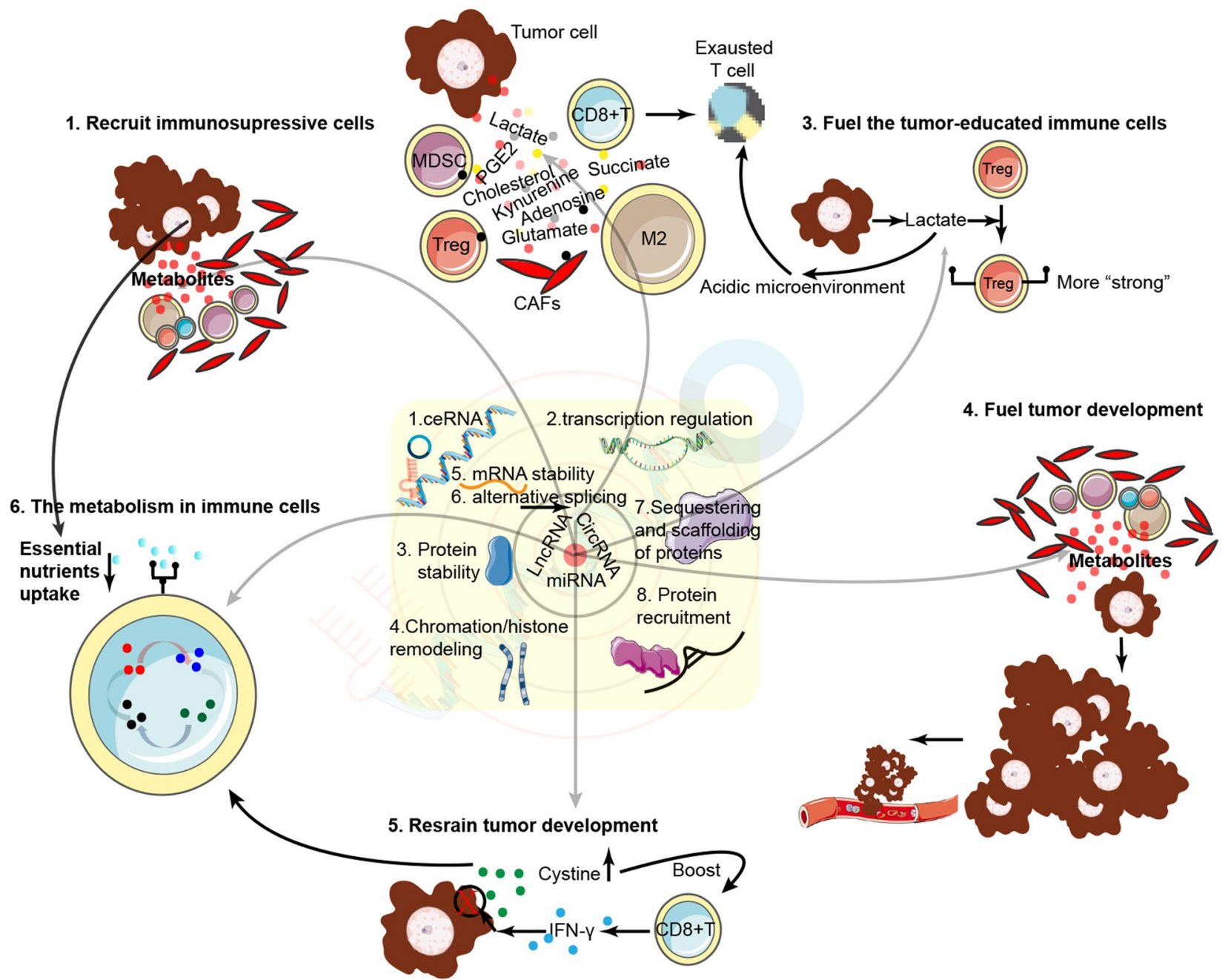

Fig. 1 Noncoding RNAs regulate biological functions through multiple mechanisms, including ceRNA, transcriptional regulation, stabilizing/ destabilizing proteins, chromatin/histone remodeling, stabilizing/destabilizing mRNAs, alternative splicing, sequestering and scaffolding of proteins and protein recruitment. Hence, given their polyfunctionality, noncoding RNAs may serve as hinges bridging metabolic activity and immune responses. Common patterns for the interaction of metabolism and the immune microenvironment were as follows: metabolites recruit or exclude immunosuppressive cells, damage or maintain the function of antitumor cells and fuel or restrain tumor-educated immune cells and tumor development

Nonetheless, tumor-derived lactate is not toxic to every cell type in the microenvironment. A recent study reported that lactate exposure enhances the function of Tregs. Lactate uptake is dispensable for the function of peripheral Treg cells but required within tumors. Blocking the uptake of lactate in Treg cells leads to slower tumor growth and an increased response to immunotherapy [14].

\section{Glutamate}

Most tumor cells consume glutamine at a high rate to sustain their rapid growth. Intriguingly, they simultaneously excrete glutamate, the first intermediate in glutamine metabolism. The reason why tumor cells are addicted to glutamine metabolism but upregulate glutamate excretion remains unclear. Nilsson et al. explained that glutamate excretion may help tumor cells increase the nucleotide synthesis rate to sustain growth [51]. However, based on accumulating evidence, tumorderived glutamate facilitates tumor immune evasion. Glutamate exposure exerts a direct inhibitory effect on $\mathrm{T}$ cell proliferation and activation [52]. Excess accumulation of glutamate in the microenvironment restrains the uptake of cystine by antigen-activated $\mathrm{T}$ cells through the 
cystine-glutamate antiporter (xCT) and further dampens antitumor immunity [53]. Glutamine blockade not only abrogates the proliferation of tumor cells but also overcomes tumor immune evasion [54].

\section{Kynurenine}

Kynurenine, the first degradation product in the indoleamine 2,3-dioxygenase (IDO)-dependent tryptophan degradation pathway, has been reported to regulate immune cell function [55]. Kynurenine induces and activates aryl hydrocarbon receptor (AhR) and thereby upregulates PD-1 expression [56]. Moreover, an interaction between kynurenine and AhR generates more regulatory $\mathrm{T}$ cells by inducing naive $\mathrm{T}$ cell differentiation [57]. Furthermore, kynurenine depletion reverses IDOmediated immune suppression and markedly increases the intratumor infiltration and proliferation of polyfunctional CD8+lymphocytes [58].

\section{Adenosine}

The adenosinergic pathway is a major immunosuppressive mechanism and an attractive novel therapeutic target for cancer [15]. Meanwhile, extracellular adenosine serves as an essential immunosuppressive metabolite that restrains the maturation of NK cells and tumorreactive effector $\mathrm{T}$ cells and then impairs antitumor immune responses [59, 60]. In contrast, inhibition of the adenosine receptor reduces the expression of $\mathrm{T}$ cell coinhibitory receptors and improves effector function for enhanced checkpoint blockade in preclinical cancer models [61]. In addition, the differentiation of regulatory $\mathrm{T}$ cells is obviously decreased upon inhibition of adenosine receptor [62]. The application of adenosine $A_{2 A}$ receptor antagonists for cancer immunotherapy in recent decades was summarized in a review [63].

\section{Prostaglandin E2}

As an essential homeostatic factor, prostaglandin E2 (PGE2) is also an important mediator of immunopathology in cancer. PGE2 directly impairs the function of NK cells through a mechanism involving the suppression of responsiveness to interleukins $[64,65]$ and indirectly restrains the NK cell function by abrogating the help from its adjuvant cells [66]. PGE2 also affects the induction of antigen-specific immune responses through the multifaceted regulation of DC functions to substantially reduce $\mathrm{T}$ cell-mediated immunity [67-69]. The inhibition of cytotoxic $\mathrm{T}$ lymphocytes mediated by PGE2 also contributes to tumor immune evasion [70, 71]. Moreover, PGE2 is also involved in the process of Ig class switching in activated B cells [72], Th cell polarization [73] and Th17 differentiation [74]. Notably, tumor-derived PGE2mediated activation of nuclear p50 NF-kB epigenetically shifts the response of monocytic cells to IFN- $\gamma$ toward an immunosuppressive phenotype, which enhances the anticancer properties of IFN- $\gamma[75]$.

\section{Other metabolites}

In addition to the abovementioned classical immunoregulatory metabolites, recent studies also reported that some other tumor-derived metabolites potentially affect the function of immune cells. Fatty acids play an important role in the pathophysiological function of immune cells [17, 76-79]. Interestingly, recent studies showed that not all types of fatty acids exert the same function in antitumor immunity. Excess saturated fatty acids impair antigen presentation and NKT function by reducing CD1d expression on the cell surface, while polyunsaturated fatty acids decrease cancer progression by inducing an antitumor immune response [80]. Even as enantiomers, S-2-hydroxyglutarate treatment significantly increases the in vivo proliferation, persistence and antitumor activity of adoptively transferred CD8+ T cells [81], while tumor-derived R-2-hydroxyglutarate induces a perturbation in nuclear factor of activated $\mathrm{T}$ cell transcriptional activity and polyamine biosynthesis, leading to the suppression of $\mathrm{T}$ cell activity [82].

We summarized the reported metabolites involved in immune regulation in Table 1 . In addition, their relationships with noncoding RNAs, which we will discuss in the following sections, are listed in Table 1.

\section{The metabolism of tumor-educated cells regulates the function of immune cells}

Cancer-associated fibroblasts (CAFs) are some of the most critical components of the tumor stroma and not only provide physical support for tumor cells but are also key functional regulators of the tumor microenvironment. According to a recent study, CAFs reduce the percentage of the antitumor Th1 subset through lactatedependent, SIRT1-mediated deacetylation/degradation of the T-bet transcription factor [10]. In addition, CAF exposure also increases the level of infiltrating Treg cells by driving naive $\mathrm{T}$ cell polarization through a mechanism dependent on lactate-mediated NF-kB activation and FoxP3 expression [10].

MDSCs decrease the availability of metabolites critical for $\mathrm{T}$ cell functions through multiple pathways. For example, MDSCs deplete L-arginine through four different enzymes, including nitric oxide synthases (NOS1-3), arginases (ARG-1 and ARG-2), arginine-glycine amidinotransferase and L-arginine decarboxylase [83]. In addition, MDSCs also increase the uptake of L-arginine from the tumor microenvironment by the CAT-2B transporter [84]. 


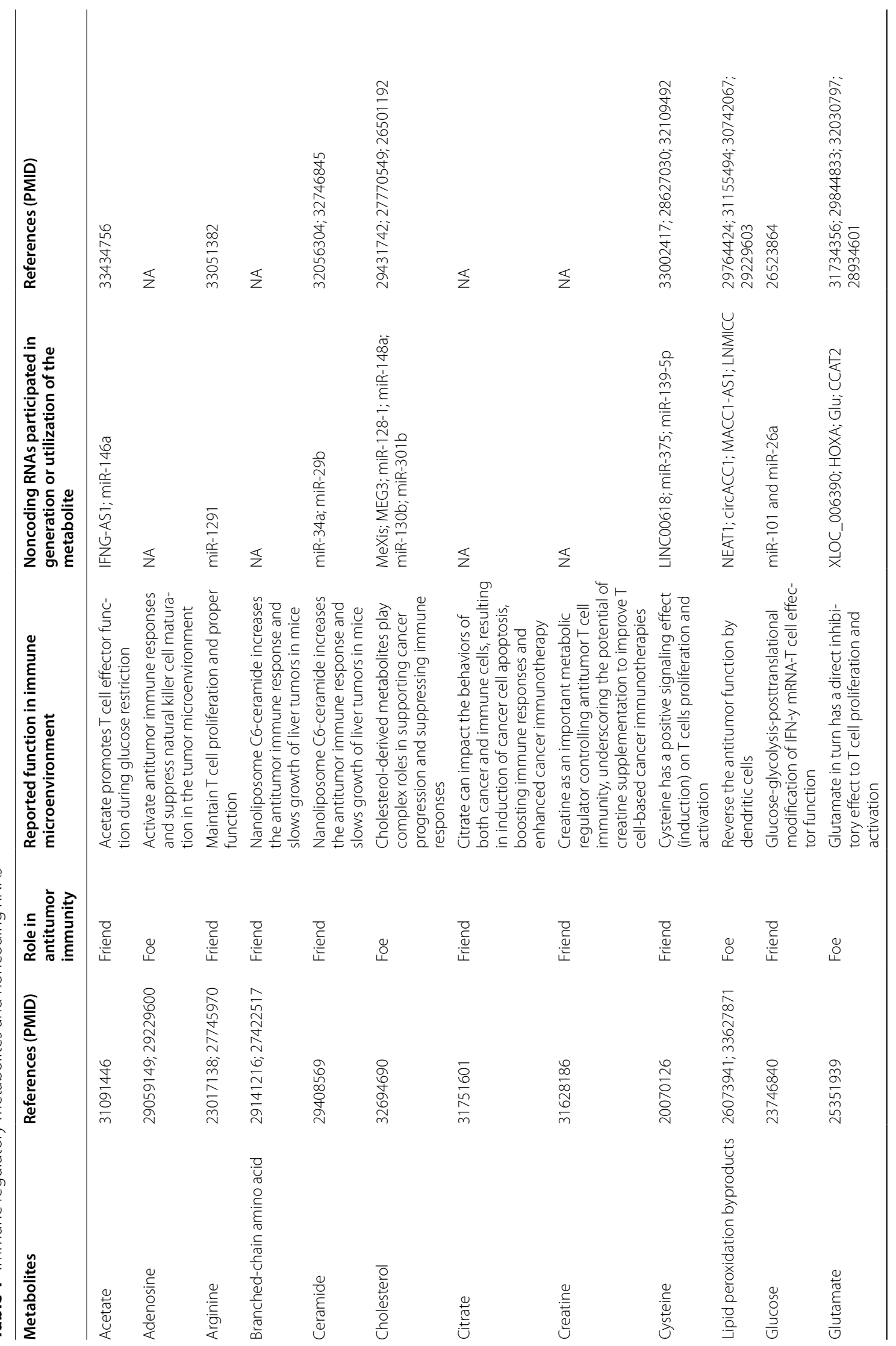




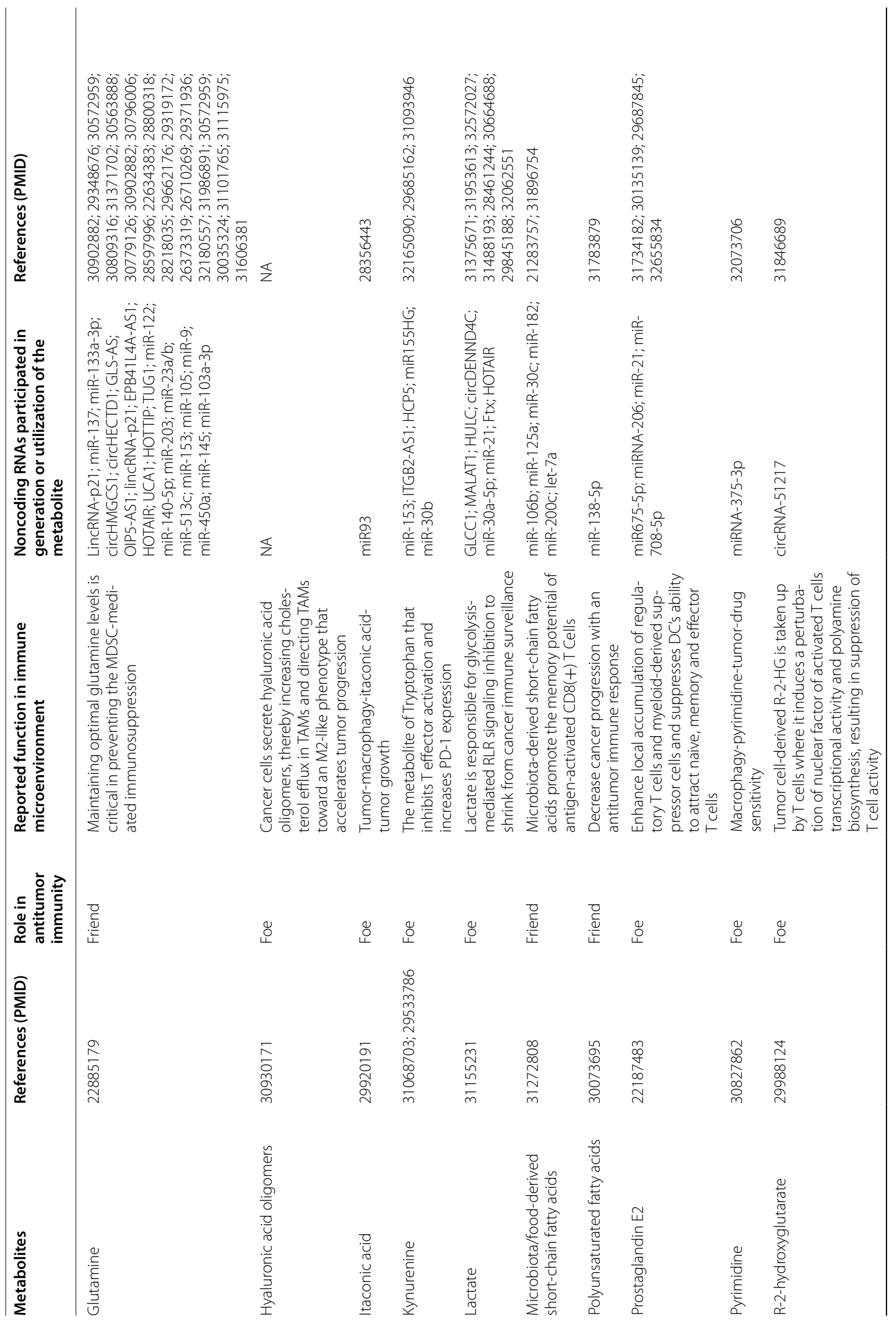




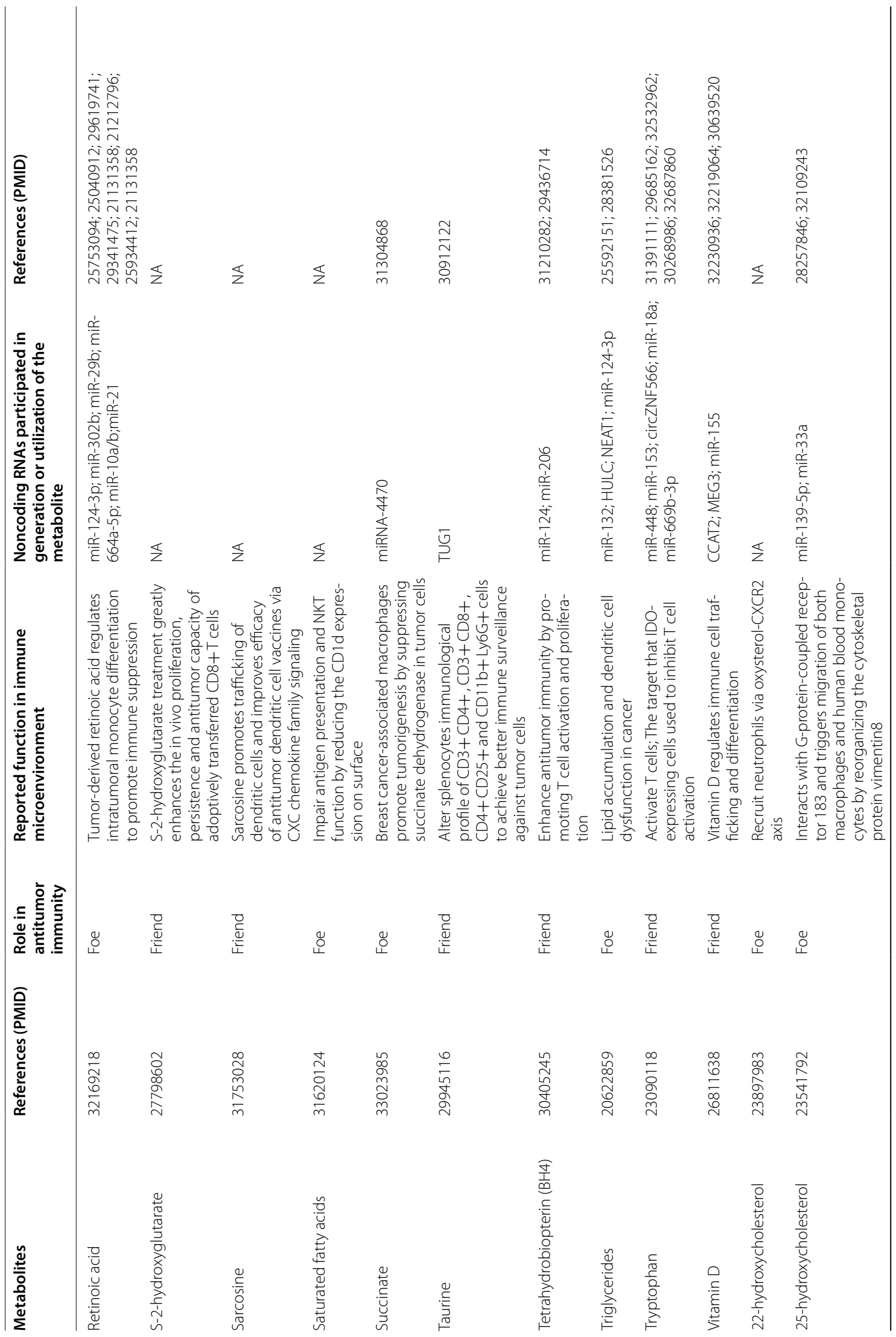




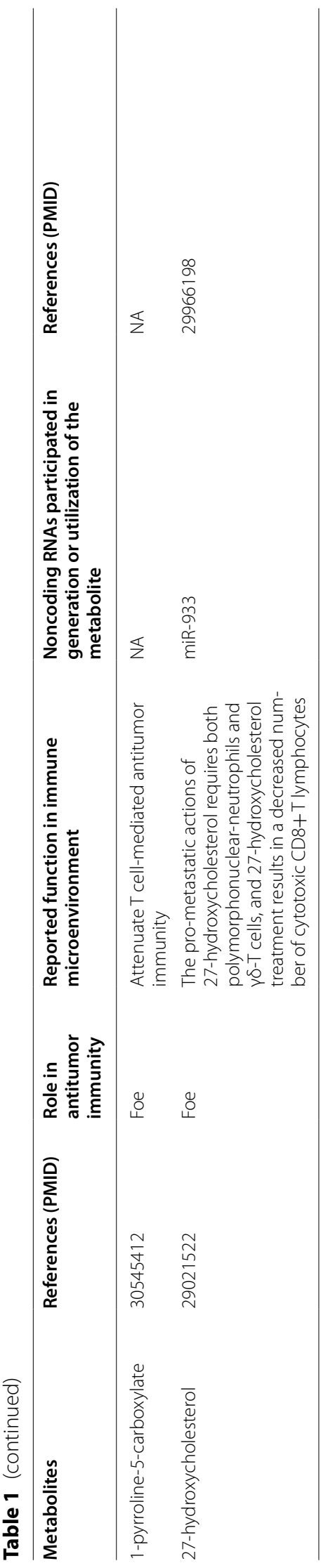


The metabolism of tumor-educated cells fuels the progression of tumor cells

Many studies have reported that the metabolic activity of tumor-educated cells supports the proliferation and metastasis of tumor cells. As shown in the recent study by Sun et al., CAF-derived lactate promotes tumor cell progression by activating the TGF $\beta 1$ signaling pathways and enhances mitochondrial activity in tumor cells [85]. Tumor cells also take up lactate secreted by CAFs to fuel the TCA cycle, accumulation of oncometabolites and subsequent hypoxia-mediated EMT [86]. In addition, macrophage-derived succinate is likely a significant oncometabolite that induces tumor development by activating the TCA cycle [87]. Cancer cells can educate stromal cells to enhance their ability to use different nutrient sources for glutamine synthesis, which then supports tumor cell mitochondrial activity and de novo purine biosynthesis through glutaminolysis [88-90].

\section{Tumor metabolism regulates the recruitment of immune cells and remodels the physicochemical properties of the microenvironment}

The metabolic activity of tumor cells has been reported to modulate gene transcription through multiple mechanisms, such as epigenetic modification [91-93]. Hence, a plausible speculation is that altered tumor metabolism disturbs the expression of some molecules involved in immune cell recruitment. $\mathrm{Li}$ et al. reported that glycolysis restriction inhibits the expression of granulocyte colonystimulating factor (G-CSF) and granulocyte macrophage colony-stimulating factor (GM-CSF), which are essential chemotaxis molecules that recruit MDSCs [94]. Mechanistically, glycolysis inhibition restrains the expression of liver-enriched activator protein (LAP) through the AMPactivated protein kinase (AMPK)-ULK1 and autophagy pathways, whereas LAP controls G-CSF and GM-CSF expression to support MDSC development.

\section{The essential metabolic activities for immune cells to maintain normal function}

Low tryptophan levels lead to cell cycle arrest and T lymphocyte apoptosis by activating the general control nonderepressible (GCN)-2 kinase [95]. The accumulation of tryptophan metabolites in the micromolar range in tumors leads to the differentiation of CD4 $+\mathrm{T}$ cells into a regulatory phenotype by binding to the aryl hydrocarbon receptor (AHR) and a reduction in T cell cytotoxicity [57]. In addition, lactate dehydrogenase inhibition promotes $\mathrm{CD} 8+\mathrm{T}$ cell stemness and antitumor immunity [96].

STAT3 activation-induced fatty acid oxidation in CD8+ $\mathrm{T}$ effector cells is critical for obesity-induced breast tumor growth [97]. In contrast, tumor-infiltrating
MDSCs tend to increase fatty acid uptake and activate fatty acid oxidation (FAO). Pharmacological inhibition of FAO blocks immune inhibitory pathways and the functions of these immunosuppressive cells to decrease their production of inhibitory cytokines. FAO inhibition alone significantly delays tumor growth in a $\mathrm{T}$ cell-dependent manner and enhances the antitumor effect of immunotherapy [98].

\section{Immunostromal cells regulate the metabolism in tumor cells}

Breast cancer-associated macrophages promote tumorigenesis by suppressing succinate dehydrogenase activity in tumor cells. The decrease in SDH levels in tumor cells results in the accumulation of succinate, which increases the stability of the transcription factor HIF $1 \alpha$ and reprograms cell metabolism to a glycolytic state [99]. In turn, HIF1 $\alpha$ and glycolysis activation contribute to PD-L1 expression and failure of immunosurveillance, as previously observed in other cells in the tumor microenvironment [99, 100]. Tumor-associated macrophages (TAMs) secrete TNF $\alpha$ to promote tumor cell glycolysis, whereas depletion of TAMs by clodronate is sufficient to abrogate aerobic glycolysis [101]. TAM depletion leads to a significant increase in PD-L1 expression in aerobic cancer cells.

\section{The regulatory pattern and mechanism of noncoding RNAs in tumor biology}

The concept of noncoding RNAs

Noncoding RNAs constitute approximately $60 \%$ of the transcriptional output of human cells and have been shown to regulate numerous cellular processes and pathways under developmental and pathological conditions [25]. Based on the threshold of 200 nucleotides for RNA length, noncoding RNAs have been divided into lncRNAs and small RNAs [102], and the latter are further classified into several distinct RNAs, such as miRNAs, small nucleolar RNAs (snoRNAs) and piwiRNAs (piRNAs) [103]. Noncoding RNAs exert their biological functions through multiple mechanisms that bypass translation, such as inducing instability of target mRNAs [104], competitive endogenous networks [29], interactions with proteins [105] and transcriptional regulation [106]. Although the majority of noncoding RNAs have little protein-coding potential, many studies recently reported that some noncoding RNAs, such as circRNAs and lncRNAs [107, 108], potentially exert their functions by encoding peptides and regulating cancer development [109].

\section{Regulatory patterns and mechanisms of noncoding RNAs Competing Endogenous RNA}

LncRNAs and circRNAs can function as endogenous miRNA sponges [110-114]. ceRNAs communicate with 
each other by competing to bind to common miRNAs, thereby dictating miRNA availability [29]. The complementarity between the seed region of the miRNA and the $3^{\prime}$ untranslated region of the target mRNA mediates the cleavage of the latter [115]. Hence, lncRNAs or circRNAs could rescue the expression of some genes that are essential for cancer development by binding to their target miRNAs. In recent decades, ceRNA mechanisms have been shown to play important roles in tumor biology [28, $31,116]$. Different ceRNA combinations regulate the initiation $[117,118]$, growth [119-121], progression [122124], metastasis [125-127], chemoresistance [128-130], apoptosis [121, 131, 132], stemness [133-135], recurrence [136-138] and metabolism [139-141] in various tumors. Moreover, the ceRNA network also modulates the tumor microenvironment by regulating stromal formation [142, 143], angiogenesis [144-146] and immune cell infiltration or function [147-150].

\section{Transcriptional regulation}

Many noncoding RNAs have been reported to directly regulate gene transcription or indirectly affect transcription factors $[29,151-153]$. Li et al. have reported a class of circRNAs associated with RNA polymerase II in human cells, which is called ElciRNAs. In the ElciRNAs, exons are circularized with introns 'retained' between exons. These epithelial circRNAs are predominantly localized in the nucleus, interact with U1 snRNP and promote the transcription of their parental genes [151]. Similarly, lncRNAs were also reported to regulate transcription by binding to histone-modifying complexes, DNA binding proteins and RNA polymerase II [154]. An increasing number of studies have also shown that miRNAs may mediate transcriptional gene activation or silencing, which implies that miRNAs may not exclusively function at the posttranscriptional level. For instance, miR-373 induces the transcription of both E-cadherin and cold-shock domain-containing protein 2 [155], and miR-205 induces the transcriptional activation of the tumor suppressor genes IL24 and IL32.

\section{Protein stability}

Many noncoding RNAs have been shown to regulate protein stability. For example, the lncRNA LINRIS blocks the K139 ubiquitination of IGF2BP2, an oncogenic RNAbinding protein, maintaining its stability through the autophagy-lysosome pathway [156]. Similarly, another lncRNA, NEAT1, also directly binds to the DDX5 protein and regulates its stability, which sequentially activates Wnt signaling and exerts oncogenic functions [157]. The circRNA CDR1as was also reported to stabilize the p53 protein by preventing its ubiquitination. CDR1as directly interacts with the p53 DBD domain and thus disrupts
p53/MDM2 complex formation, which inhibits gliomagenesis [158].

\section{Chromatin/histone remodeling}

Liquid-liquid phase separation is the basis for the formation of membrane-less organelles in cells and is involved in many biological processes [159]. Recently, many studies have shown that phase separation participates in chromatin/histone remodeling, and noncoding RNAs may also play an important role in this process [160163]. Daneshvar and colleagues reported that the lncRNA DIGIT is required for bromodomain and extraterminal domain protein BRD3 to form phase-separated condensates [164], which is important for regulating endoderm differentiation. In addition to liquid-liquid phase separation, the lncRNA Xist silences the transcription of one $\mathrm{X}$ chromosome during development in female mammals by directly interacting, recruiting and activating a series of proteins and further deacetylating histones to exclude Pol II from the X chromosome [165]. Another approach by which noncoding RNAs indirectly modulate chromatin or histones is via epigenetic regulators. For instance, the IncRNA GATA6-AS epigenetically regulates gene expression through an interaction with LOXL2-mediated changes in histone methylation [166]. Reciprocally, H3K27 acetylation induces the expression of the lncRNA colon cancer-associated transcript-1 (CCAT1), whose overexpression may induce tumorigenesis in many cancers [167].

\section{mRNA stability}

In addition to miRNAs, other noncoding RNAs also showed the ability to directly influence mRNA stability. Chen recently revealed that circNSUN2 is upregulated in colorectal cancer and promotes liver metastasis by stabilizing the HMGA2 mRNA [168]. Similarly, Wu et al. reported that the lncRNA THOR increases osteosarcoma cell stemness and migration by increasing SOX9 mRNA stability. Further experiments indicated that the lncRNA THOR directly binds to the middle region of the SOX9 3'UTR, thereby increasing SOX9 mRNA stability and expression [169].

\section{Alternative splicing}

Alternative splicing is tightly associated with the transcription of noncoding RNAs, particularly circRNAs [170]. However, noncoding RNAs may subsequently regulate the alternative splicing of other genes [171]. Some lncRNAs, such as NEAT1 and MALAT1, potentially interact with splicing factors. An intimate association was observed between them and SC35 SF-containing nuclear speckles in both human and mouse cells, suggesting their participation in mRNA splicing [172]. Their 
role was further confirmed by the results of an RNA FISH analysis. Serine/arginine-rich (SR) proteins are a conserved family of proteins that are mainly involved in splicing. In addition, a continuous phosphorylation or dephosphorylation cycle of SR proteins is required for proper premRNA splicing and the regulation of AS patterns. According to recent studies, one SR protein, SRp40, directly recognizes NEAT1, exhibiting a dynamic association throughout adipocyte differentiation. Then, an increased concentration of the phosphorylated SRp40 protein after release from NEAT1 was proposed to promote the splicing of the PPAR 2 mRNA [173].

\section{Sequestering, scaffolding and recruitment of proteins}

Sun et al. reported that the novel lncRNA GClnc1 functions as a modular scaffold to recruit key components of the histone methyltransferase complex. Then, many oncogenic genes, such as SOD2, are activated epigenetically and mediate tumorigenesis [174]. In addition, Jie et al. [175] identified a novel circRNA named circMRPS35, which is associated with the clinicopathological characteristics and prognosis of patients with gastric cancer. Mechanistically, circMRPS35 functions as a scaffold to recruit histone acetyltransferase KAT7 to the promoters of the FOXO1 and FOXO3a genes, which catalyzes the acetylation of H4K5 in their promoters. Notably, circMRPS35 directly binds to FOXO1/3a promoter regions, thereby inducing the transcription of FOXO1/3a and triggering subsequent expression of downstream oncogenic genes [175].

\section{Protein coding}

Although noncoding RNAs are generally recognized to lack a protein-coding capability, recent studies have gradually shown that some of these molecules encode peptides and regulate biological processes in cancers. Huang and colleagues discovered that the lncRNA HOXB-AS3 encodes a conserved 53-aa peptide that suppresses colon cancer growth itself instead of its parental lncRNA [176]. In addition, Zhang et al. documented that an endogenous circRNA generated from a lncRNA encodes a regulatory peptide using ribosome nascent-chain complex-bound RNA sequencing [177]. This peptide directly interacts with the polymerase-associated factor complex and inhibits the transcriptional elongation of multiple oncogenes, thereby fueling glioblastoma tumorigenesis. Notably, Pan et al. previously summarized three categories of noncoding RNA-encoded peptides: miRNA-encoded peptides, a 90 residue-long regulatory peptide encoded by an IncRNA, and a circRNA-encoded truncated NCX1 protein [178].

\section{Other functions}

Significant enrichment of miRNAs has been observed in the nucleolar region of cells [179]. Many studies have reported the potential biological functions of nucleolar miRNAs in biological processes [180, 181]. For example, nucleolar RNA was observed to be colocalized with $28 \mathrm{~S}$ ribosomal RNA, suggesting that miRNAs may associate with ribosome subunits at an early stage of ribosome biogenesis [182].

\section{Noncoding RNAs regulate both tumor metabolism and the immune microenvironment}

Since noncoding RNAs regulate many aspects of gene expression from pretranscriptional to posttranslational processes, as mentioned above, they are expected to exert effects on numerous cellular activities. In this context, miRNAs, lncRNAs, circRNAs and their regulatory networks may participate in the remodeling of tumor metabolism and the immune microenvironment (Fig. 2).

Tumor metabolism has always been a field studied by a wide range of researchers. Treatments targeting the addiction and dependence of tumor cells on reprogrammed metabolic pathways results in stringent tumor suppression in vivo and in vitro $[9,183,184]$. Many studies have reported that miRNAs, lncRNAs and circRNAs contribute to tumor metabolic rewiring, including glycometabolism [185], lipid metabolism [186] and amino acid metabolism [187]. Mechanistically, noncoding RNAs either directly regulate the mRNA and protein expression of metabolic enzymes or indirectly interact with the key factors that regulate the synthesis of metabolic enzymes.

Meanwhile, an increasing number of studies have emphasized the role of noncoding RNAs in remodeling the tumor microenvironment, which is involved in the immune cell differentiation trajectory, function and infiltration [188-194].

\section{Glycometabolism, noncoding RNAs and the immune microenvironment}

Aerobic glycolysis or the Warburg effect is a representative hallmark of tumor metabolism. Through ceRNA mechanisms [139, 195-201], nucleolar translocation [202], protein interactions [156, 203, 204] and alternative splicing [205], noncoding RNAs reprogram glycolytic activity in tumor cells.

Interestingly, macrophage-derived lncRNAs were recently shown to regulate glycolysis in tumor cells. Extracellular vesicle-packaged HIF- $1 \alpha$-stabilizing lncRNA (HISLA) from tumor-associated macrophages regulates aerobic glycolysis in breast cancer cells by inhibiting the hydroxylation and degradation of HIF- $1 \alpha$. Reciprocally, the glycolytic product lactate upregulates 


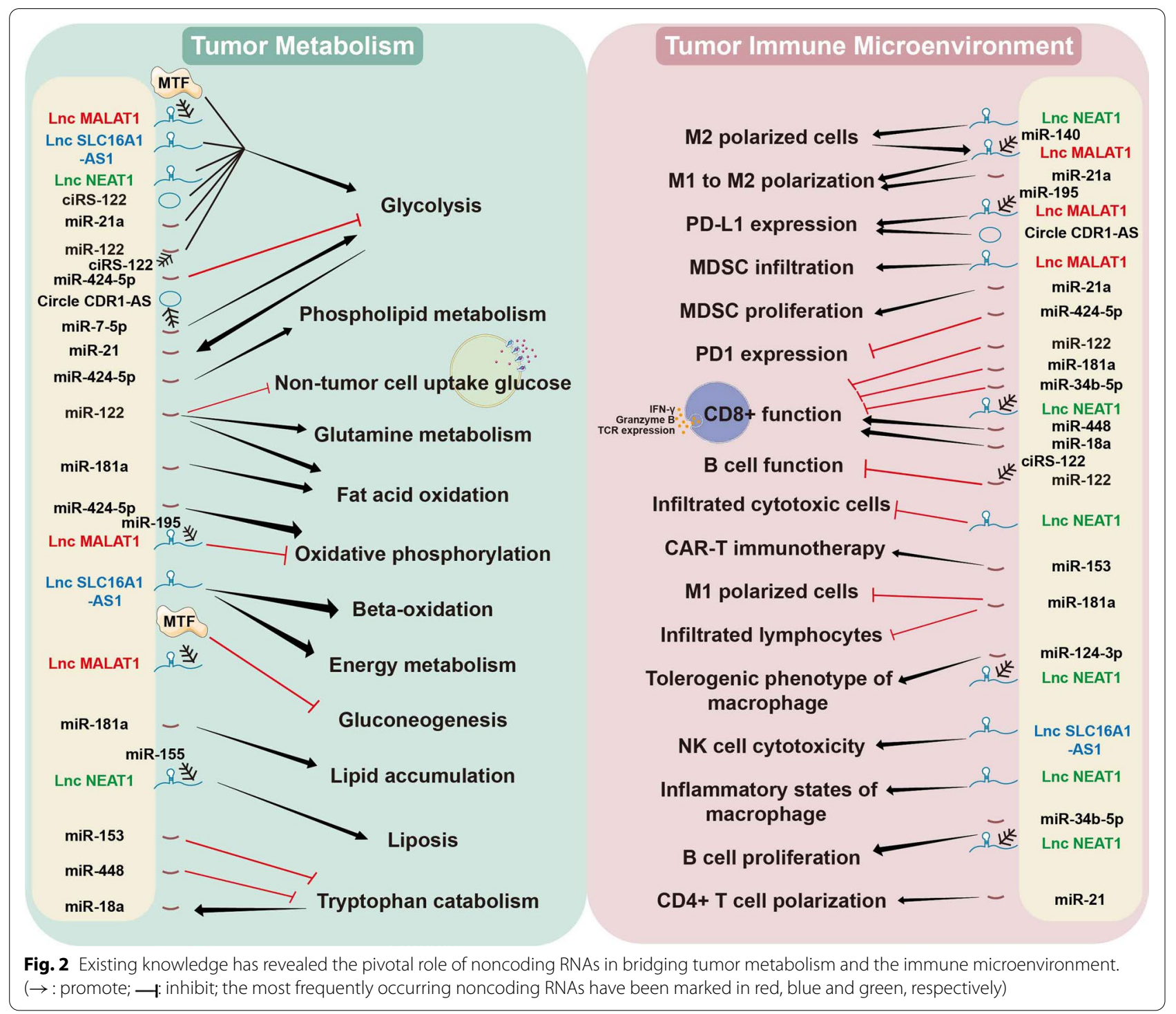

the expression of HISLA in tumor-associated macrophages, which constitutes a feed-forward loop between TAMs and tumor cells [206]. Similarly, CAF-derived lactate modulates the polarization of $\mathrm{CD} 4+\mathrm{T}$ cells by reducing the infiltration of Th1 cells and increasing the infiltration of Treg cells, a process in which miR-21 plays an important role [10].

In addition, Zhao et al. found that ovarian cancer cells imposed a glucose restriction on effector $\mathrm{T}$ cells and impaired their function by upregulating the expression of miR-101 and miR-26a, which constrained the expression of the methyltransferase EZH2 and the activity of the Notch pathway [207]. Consequently, the function of $\mathrm{T}$ cells was compromised due to the deficiency in Notchmediated Bcl-2 signaling and polyfunctional cytokine expression [207]. Cancer-associated fibroblasts also mediate the upregulation of LINC00092, which further promotes glycolytic activity in ovarian cancer cells by stabilizing fructose-2,6-biphosphatase [208].

The IncRNA MALAT1 has been reported to regulate tumor cell metabolism through multiple mechanisms. For example, Malakar et al. reported that a metabolic transcription factor, TCF7L2, is stabilized by MALAT1 and mediates the upregulation of glycolytic activity but decreases gluconeogenic enzymes via the mTORC14EBP1 axis [209]. Similarly, Nanni et al. showed that MALAT1 silencing reduces the expression of some metabolic enzymes, including malic enzyme 3 , pyruvate dehydrogenase kinases 1 and 3 and choline kinase A, which promotes a glycolytic phenotype and increased lactate 
production [210]. As we have described in the previous sections, the activation of glycolysis in tumor cells triggers an immunosuppressive tumor microenvironment. Hence, MALAT1 is expected to be a negative regulator of antitumor immunity. In fact, many studies have shown that MALAT1 exerts immunosuppressive effects in recent years. As shown in the study by Wang et al., MALAT1 sponges miR-195 to increase the expression of PD-L1, thereby promoting immune escape in diffuse large B cell lymphoma [147]. Likewise, through a ceRNA mechanism, MALAT1 overexpression contributes to angiogenesis and impairs M1 macrophage polarization by binding to miR-140 in hepatocellular carcinoma [211]. However, not all studies support the role of MALAT1 in promoting the immune evasion of tumors. Zhou et al. noted a negative correlation between the relative expression of MALAT1 and the proportion of MDSCs, while knockdown of MALAT1 significantly increases the proportion of MDSCs in the peripheral blood of patients with lung cancer [212].

Interestingly, immune cells facilitate tumorigenesis by inducing MALAT1 expression. For example, IL8 secreted from M2-polarized macrophages promotes prostate cancer progression via the STAT3/MALAT1 pathway, while knockdown of MALAT1 expression levels in prostate cancer cell lines inhibits cell proliferation, invasion and tumor formation [213].

As one of the most aberrantly expressed miRNAs detected in human cancers, miR-21a was reported to increase lactate generation and decrease oxygen consumption in lung cancer cells. Mechanistically, miR-21a directly targets fructose-1,6-biphosphatase and thereby reduces oxidative phosphorylation and increases glycolysis [214]. In this context, miR-21a may contribute to the formation of an immunosuppressive microenvironment by releasing glycolytic byproducts. Notably, miR-21a within MDSCs maintains the immunosuppressive microenvironment by enhancing the infiltration and function of polymorphonuclear MDSCs through the suppression of the MLL1 complex, while tumor-derived miR-21 also promotes the expansion of MDSCs by downregulating PDCD4 expression $[215,216]$. Additionally, miR-21 promotes the transformation of macrophages toward M2 subtypes and further compromises antitumor immunity [217].

\section{Lipid metabolism, noncoding RNA and the immune microenvironment}

According to a previous study, miR-424-5p modulates glucose metabolism during tumor growth and metastasis [218]. However, recent studies also showed that it affects lipid metabolism in cancer cells. Notably, miR-424-5p binds to ACSL4 and abrogates ferroptosis, a cell death mechanism dependent on lipid peroxidation, in ovarian cancer cells. In contrast, knockdown of miR-424-5p increases the sensitivity of ovarian cancer cells to ferroptosis inducers [219]. Moreover, miR-424-5p reduces the expression of phospholipid scramblase, which is responsible for collapsing lipid asymmetry by catalyzing bidirectional transbilayer movement of the major classes of phospholipids [220]. As a tumor suppressor, miR-424-5p also participates in regulating the expression of effector cytokines in $\mathrm{T}$ cells by promoting PD-L1 degradation [221]. The paradox is that miR-424-5p abrogates ferroptosis but promotes antitumor immunity; however, previous studies showed that ferroptosis potentially serves as an immunogenic form of cell death that triggers robust antitumor immunity [222, 223]. Future studies are expected to elucidate the mechanism underlying this contradiction. In addition, miR-122 controls fatty acid $\beta$ oxidation by interacting with SIRT6 and predicts the prognosis of hepatocellular carcinoma [224]. Through immunoregulatory mechanisms, exosome-derived miR122 drives tumor immune evasion by regulating TCR signaling and TNF $\alpha$ secretion [192].

As shown in previous studies, miR-181a is an essential modulator that regulates immune responses [192, 225], such as $T$ cell differentiation [226, 227]. A recent study proposed that miR-181a also inhibits innate immune signaling by interrupting the STING-associated IFNY response and lymphocyte infiltration in patients with cancer [228]. Moreover, Jiang et al. showed that exosome-derived miR-181a promotes the expansion of early-stage MDSCs by targeting PIAS3, a member of the protein inhibitor of activated STAT family, in breast cancer [229]. Chu et al. also showed that miR-181a decreases the expression of genes involved in lipid synthesis and increases the expression of genes involved in $\beta$-oxidation, subsequently inhibiting lipid accumulation in transgenic mouse models [230].

The long noncoding RNA NEAT1 has been reported to drive tumorigenesis and metastasis in multiple cancers $[157,231-234]$. Liu et al. recently reported that lncRNANEAT1 modulates the expression of adipose triglyceride lipase (ATGL) and disrupts lipolysis in hepatocellular carcinoma cells [235]. In contrast, NEAT1 knockdown attenuates HCC cell growth through miR-124-3p and rescues lipolysis. NEAT also manifests an immunoregulatory function in cancers. Tumor samples with high levels of cytotoxic CD8+infiltration express NEAT1 at lower levels. Furthermore, NEAT1 promotes tumor growth by inhibiting cytotoxic $\mathrm{T}$ cell-mediated immunity through a decrease in the expression of cyclic GMP-AMP synthase stimulator of interferon genes [236]. NEAT1 also induces the activation of the NLRP3 inflammasome in dendritic cells or macrophages to regulate their functions and 
phenotypes [237, 238]. In addition, NEAT1 sponges miR214 to regulate M2 macrophage polarization by regulating $\mathrm{B} 7-\mathrm{H} 3$ in multiple myeloma, which further promotes tumor immune evasion [239].

\section{Amino acid metabolism, noncoding RNAs and the immune microenvironment}

Tryptophan metabolism has long been recognized as an immunosuppressive mechanism in cancers [240-242]. Recent studies have shown that many noncoding RNAs regulate IDO-1 expression, which catalyzes the conversion of tryptophan into kynurenine and promotes immune evasion by activating $\mathrm{T}$ regulatory cells and MDSCs and suppressing the functions of effector $\mathrm{T}$ cells and natural killer cells [243]. According to Wang et al., IDO1 is overexpressed in colorectal tumors and is negatively associated with patient survival. Interestingly, IDO1 expression is reduced by miR-153, which targets the 3' untranslated region of IDO1 transcripts. Overexpression of miR-153 significantly inhibits tumor growth and enhances CAR T cell immunotherapy [38]. This finding was validated by another study showing that miR-153 decreases tryptophan catabolism and inhibits angiogenesis in bladder cancer [33]. In addition, Lou et al. screened miRNAs targeting IDO1 using a dual luciferase reporter assay. Their results showed that miR-448 significantly downregulates IDO1 protein expression and thereby suppresses the apoptosis of CD8+ T cells [37]. Notably, IDO1 also suppresses antitumor immunity through noncoding RNA-dependent mechanisms. For instance, IDO1 impairs NK cell cytotoxicity by promoting miR18a expression, which is required for NKG2D/NKG2DL silencing [39].

Glutamine addiction has long been known as the main feature of tumor metabolic rewiring that fuels tumor growth [244, 245]. As we have summarized in the previous sections, glutamine metabolism is tightly associated with tumor immune evasion. The lncRNA HOTAIR was reported to upregulate chemokine ( $\mathrm{C}-\mathrm{C}$ motif) ligand 2 and promote the proliferation of macrophages and MDSCs in hepatocellular carcinoma [246]. A plausible speculation is that HOTAIR then mediates tumor immune evasion through MDSC recruitment. Interestingly, HOTAIR was also found to increase the expression level of glutaminase, which is essential for glutamine metabolism and subsequent oncogenic processes [247]. In this context, HOTAIR may mediate the immunosuppressive response by upregulating glutamine metabolism.

\section{The role of noncoding RNAs in the metabolism of immune cells}

Given the potent functions of noncoding RNAs in multiple processes, a biologically plausible hypothesis is that noncoding RNAs in immune cells regulate many processes, such as metabolism and effector functions [248-250]. For instance, overexpression of miR-30c in macrophages promotes M1 macrophage differentiation and function by increasing glycolytic activity [251], while miR-143 inhibits glucose uptake and glycolysis by decreasing the expression of glucose transporter 1 in $\mathrm{T}$ cells to interrupt $\mathrm{T}$ cell differentiation [252].

Regarding lipid metabolism, miR-33 inhibits fatty acid oxidation in macrophages by decreasing the expression of retinoic acid-producing enzyme aldehyde dehydrogenase family 1 both in vitro and in a mouse model [253]. In addition, microRNA-150 expressed in macrophages also regulates pathological lipid trafficking [254].

Manually interrupting metabolism in immune cells has become a novel treatment modality in recent years that may function through noncoding RNAs. Sheng et al. blocked glycolysis in malignantly transformed macrophages and dendritic cells using 3-bromopyruvate (3-BrPA). They found that 3-BrPA significantly inhibited the proliferation of malignantly transformed macrophages and dendritic cells in a dose-dependent and time-dependent manner. Utilizing an online database and experimental data, they showed that 3-BrPA inhibits malignant progression via the miR-449a/MCT1 axis, which blocks lactate transport [255].

\section{Noncoding RNAs bridge metabolites and pro- or antitumor immunity}

Metabolites are one of the most active elements that regulate multifaceted biological processes in the tumor microenvironment, serving as either nutrients producing energy or wastes whose accumulation interrupts normal cellular function [256-258]. Metabolites in the microenvironment modulate antitumor immunity or immune evasion. In this section, we describe currently reported metabolites that either enhance antitumor immunity or promote immune evasion in Table 1, and noncoding RNAs participating in the generation or utilization of these metabolites are also presented.

\section{Noncoding RNAs regulate the generation or utilization of metabolites that promote antitumor immunity}

Metabolites enhance antitumor immunity through multiple mechanisms, one of the most important of which is providing essential nutritional support for tumor-killing immune cells. Arginine is important for effector T cells to maintain their antitumor activity. An increase in the L-arginine concentration triggers global metabolic rewiring, including a shift from aerobic glycolysis to oxidative phosphorylation in activated $\mathrm{T}$ cells, and promotes the generation of central memory-like cells. In vivo experiments further showed that increased arginine levels 
endowed a mouse model with higher antitumor activity and prolonged survival [259]. Interestingly, MDSCs with increased arginase I expression is part of an important mechanism that induces an immunosuppressive microenvironment by restricting the availability of arginine and restraining effector $\mathrm{T}$ cell function [260]. According to previous studies, miR-1291 targets the rate-limiting enzyme argininosuccinate synthase and reduces arginine synthesis [261]. miR-1291-5p sensitizes pancreatic carcinoma cells to arginine deprivation through the regulation of arginolysis [262]. In addition, external L-arginine also regulates the expression of many noncoding RNAs and triggers downstream biological changes [263-266].

$\mathrm{T}$ cell activation is initiated by the specific binding of the $\mathrm{T}$ cell receptor to an antigenic peptide presented by the major histocompatibility complex on the surface of an antigen-presenting cell (APC). Then, many ligations of costimulatory molecules on the surface of $\mathrm{T}$ cells are engaged and induce a downstream cascade of signaling events and pathways that regulate the clonal expansion and differentiation of naive $\mathrm{T}$ cells into effector $\mathrm{T}$ cells. These interactions were determined by investigating membrane physiology, which is maintained partially by the catabolic cleavage of sphingomyelin and the subsequent generation of ceramide [267, 268]. Some studies have reported that noncoding RNAs regulate the generation of ceramide or downstream of ceramide-mediated biological processes. For example, miR-34a causes ceramide accumulation [269], while ceramide inhibits the proangiogenic activity of multiple myeloma through miR-29b [270].

Another mechanism by which metabolites regulate antitumor immunity is epigenetic modification. For instance, acetate serves as an alternative energy source for both cancer cells and immune cells when glucose is restricted. Acetate rescues the effector function of $\mathrm{CD} 8+\mathrm{T}$ cells by promoting histone acetylation and chromatin accessibility, thus facilitating IFN- $\gamma$ gene transcription and cytokine production in an acetyl-CoA synthetase-dependent manner [271].

As we described in the previous sections, IDO-mediated tryptophan degradation was a major cause of effector $\mathrm{T}$ cell dysfunction in the tumor microenvironment. Hence, tryptophan itself is very important for the tumorkilling function of effector $\mathrm{T}$ cells. Many noncoding RNAs have been reported to affect tryptophan metabolism, enabling cells to reverse metabolism-mediated immune suppression [37-39, 272, 273]. Similarly, glucose is the basic nutrient required for the activation of various immune cells, especially effector T cells [274]. Zhao et al. reported a novel mechanism by which primary cancer imposes glucose restriction on $\mathrm{T}$ cells and affects antitumor immunity. They found that miR-101 and miR-26a were imperative factors mediating the effects of glucose deprivation on $\mathrm{T}$ cell polyfunctionality, while $\mathrm{T}$ cells were activated, and the abundance of miR-101 and miR-26a was rapidly reduced [207].

Tetrahydrobiopterin (BH4) is an important enzymatic cofactor required for the synthesis of dopamine, serotonin and nitric oxide [275]. Recently, Cronin et al. reported that $\mathrm{BH} 4$ controls antitumor immunity by increasing intratumoral expansion and function [276]. Administration of $\mathrm{BH} 4$ to animal models markedly reduces tumor growth and rescues the impaired antitumor immunity mediated by tryptophan-kynurenine metabolism [276]. Notably, BH4 metabolism could also be regulated by many noncoding RNAs [277, 278], suggesting that treatments targeting $\mathrm{BH} 4$ metabolism by modulating noncoding RNAs might be a novel modality for cancer immunotherapy.

Other small metabolites, such as vitamin D [279], taurine [280] and cysteine [281], also enhance antitumor immunity. Vitamin D regulates immune cell trafficking and differentiation, taurine alters the splenocyte immunological profile of CD3+ CD4+, CD3+ CD8+, CD4+ CD25+ and CD11b+ Ly6G+ cells to achieve better immune surveillance against tumor cells, and cysteine exerts a positive effect on $\mathrm{T}$ cell proliferation and activation. Noncoding RNAs play an important role in the production or transportation of these metabolites [282285], reciprocally, they might also exert their functions through noncoding RNAs [286-288].

\section{Noncoding RNAs regulate the generation or utilization of metabolites that fuel tumor immune evasion}

Cholesterol-derived metabolites play pivotal roles in supporting cancer progression and suppressing antitumor immune responses [289]. As shown in a recent study, tumor microenvironment-derived cholesterol increases CD36 expression and subsequent fatty acid uptake in tumor-infiltrating CD8+ T cells. Excess uptake of fatty acids triggers lipid peroxidation and ferroptosis in CD8+ $\mathrm{T}$ cells, which further leads to reduced cytotoxic cytokine production and impaired antitumor activity [290]. Even the hydroxylated products of cholesterol, 25-hydroxycholesterol or 27-hydroxycholesterol, induce immunosuppression by either promoting MDSC infiltration or decreasing CD8+ T cell numbers [291, 292]. Sallam et al. documented that the IncRNA MeXis promotes cholesterol efflux via the transcriptional regulation of the Abcal gene [293], suggesting that MeXis may exert a similar function in tumor-associated macrophages to alter $\mathrm{T}$ cell function. In addition, Wagschal et al. leveraged a meta-analysis of genome-wide association studies and identified four microRNAs, including miR128-1, miR-148a, miR-130b and miR-301b, involved in 
cholesterol-lipoprotein trafficking [294]. The metabolism of hydroxylated cholesterol is also regulated by or functions via other noncoding RNAs [295-297]. Targeting related noncoding RNAs may contribute to cholesteroldependent immune suppression. Similar to cholesterol, lipid peroxidation byproducts and triglycerides fuel abnormal lipid accumulation in tumor-associated dendritic cells and reduces their ability to prime $\mathrm{T}$ cells [298, 299]. Moreover, many noncoding RNAs have been reported to regulate lipid peroxidation byproducts [235, 300-303].

Unlike lactate and kynurenine, two well-known immunosuppressive metabolites that regulate and are regulated by many noncoding RNAs in tumor biology, itaconic acid was recently identified as a macrophage-specific metabolite that promotes tumor progression. As the product of immune-responsive gene 1-mediated (IRG1) catabolism of mitochondrial cis-aconitate, itaconic acid in tumorassociated macrophages is upregulated by tumor cells and in turn alters tumor metabolism [304]. Repression of itaconic production significantly slows tumor development. Based on in vitro experiments, miR-93s also decrease itaconic acid production through an IRG1mediated mechanism. Then, the decreased itaconic acid production mediated by miR93 further promotes and sustains M2-like polarization, even under M1-like polarizing conditions [305].

Chemotherapeutic drug resistance is a common problem faced by many patients with late-stage tumors. Many drugs are first metabolized and then exert their functions within cells, such as gemcitabine [306]. Recently, Halbrook et al. reported that macrophages in pancreatic cancer release a spectrum of pyrimidine species, which decrease gemcitabine efficacy through molecular competition at the level of drug uptake and metabolism [307]. Genetic or pharmacological depletion of tumor-associated macrophages in pancreatic cancer resensitized these tumors to gemcitabine [307]. miR-375-3p was found to be widely downregulated in human colorectal cancer cell lines and tissues and was associated with sensitivity to 5-fluorouracil. Mechanistically, miR-375-3p directly targets thymidylate synthase and is cotransported with 5-FU [308].

\section{The potential role of ncRNAs in metabolic remodeling during immune checkpoint therapy}

Approaches targeting immune checkpoints such as PD1/ PDL1 and CTLA4 have been a popular treatment modality for many cancers, including bladder cancer, melanoma, lung cancer and breast cancer [309-312]. Because the regulation of ncRNAs in tumor biology is multilayered and plastic, a plausible hypothesis is that ncRNA disturbances might determine the efficacy of ICIs. Many studies have shown that ncRNAs affect the expression levels of immune checkpoint genes. For example, miR155 increases PD-L1 expression in lymphoma cells, recruits $\mathrm{CD} 8+\mathrm{T}$ cells through the $\mathrm{PD}-1 / \mathrm{PD}-\mathrm{L} 1$ interaction and inhibits CD8+ T cells [313]. In contrast, miR873 inhibits PD-L1 expression by directly binding to its 3'-untranslated region [314]. Through ceRNA mechanisms, lncRNAs and circRNAs also regulate checkpoint expression and immune evasion [150, 315]. In addition, ncRNAs seem to affect checkpoint trafficking. Hong et al. reported that circ-CPA4 promotes the secretion of PDL1-containing exosomes and triggers immune evasion [133]. Interruption of the expression of some ncRNAs synergistically improves the efficacy of ICI treatment [316]. Notably, most of these ncRNAs have been reported to be involved in cell metabolism, including cholesterol efflux [317], glycolysis [318] and oxidative phosphorylation [319].

Interestingly, ncRNAs might also mediate side effects of ICI treatment. Xia et al. revealed that ICIs induce exosomal trafficking of miR-34a-5p from macrophages to cause cardiac injury in vivo [320]. However, few studies have focused on the direct alterations of ncRNA profiles during ICI treatment, which might become a hot field in the near future. Some questions must be answered by conducting appropriate studies. First, do ncRNAs mediate ICI resistance through metabolic rewiring? Second, do treatments targeting ncRNAs and metabolic reprogramming optimize the efficacy of ICIs, as the response rates to ICIs were unexpectedly low? Third, do specific ncRNAs exert pivotal effects on metabolic networks and dramatically reprogram the metabolic pattern to promote immune cell activation or inactivation in the antitumor microenvironment? Enriched high-throughput whole transcriptional sequencing data for samples from individuals treated with ICIs will be valuable to answer these questions.

\section{Construction of the TIMELnc manual by reviewing the transcriptomic data for $\mathbf{2 8}$ cancers in TCGA (The Cancer Genome Atlas)}

Despite the increasing number of studies reporting the roles of noncoding RNAs in tumor metabolism and the immune microenvironment, we speculated that many other noncoding RNAs involved in tumor immunity and metabolic reprogramming have yet to be identified given the broad regulatory mechanisms of noncoding RNAs in the physiopathology of tumors. LncRNAs play pivotal roles in the noncoding RNA regulatory network, and the intratumor expression of lncRNAs at the pancancer level can be accessed in public databases. In this context, we reanalyzed the transcriptomic data for 28 distinct cancers in TCGA database using the protocol shown 
A

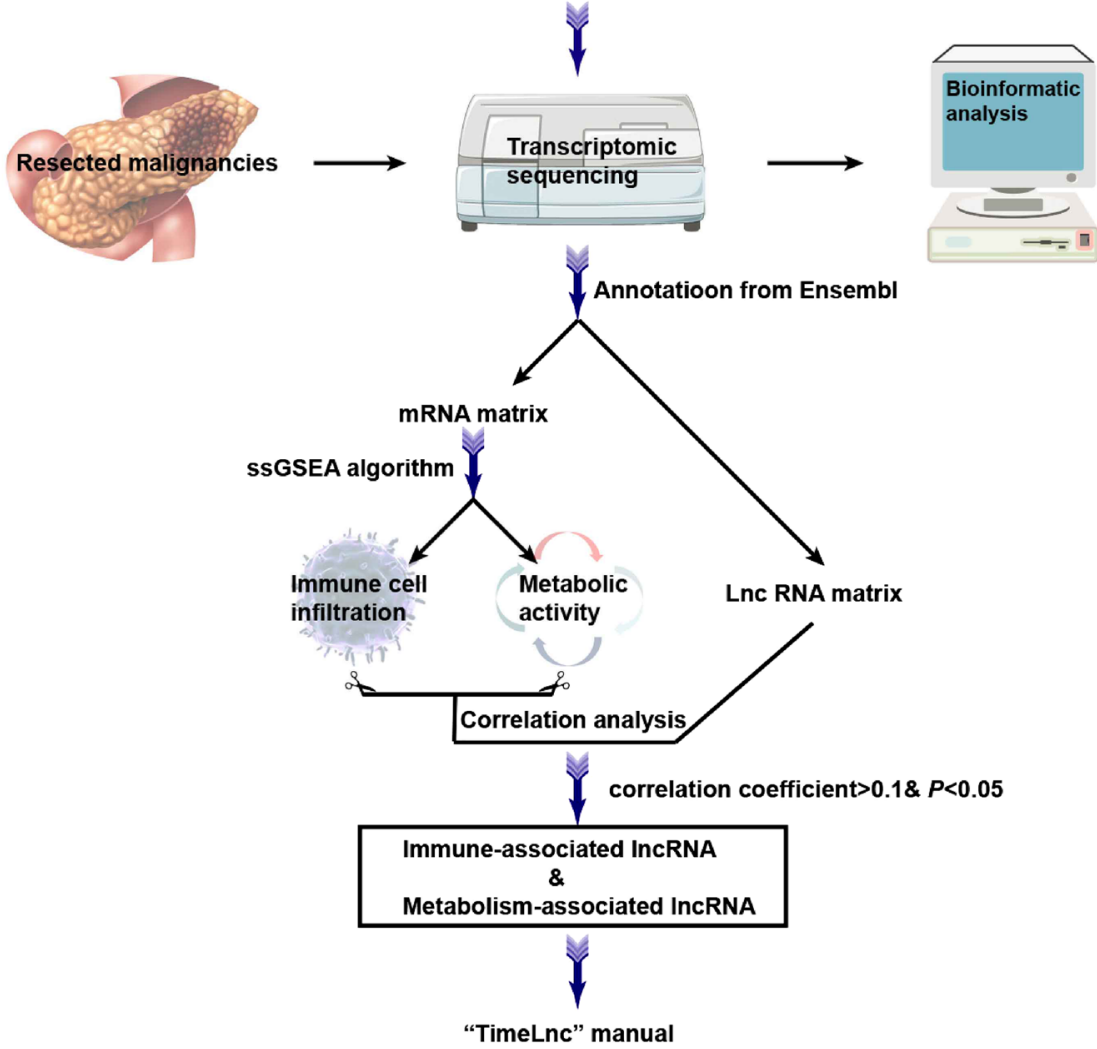

*Readers could refer to this manual to identify potential IncRNAs simultaneously regulate intratumoral metabolism and immune activity.

B

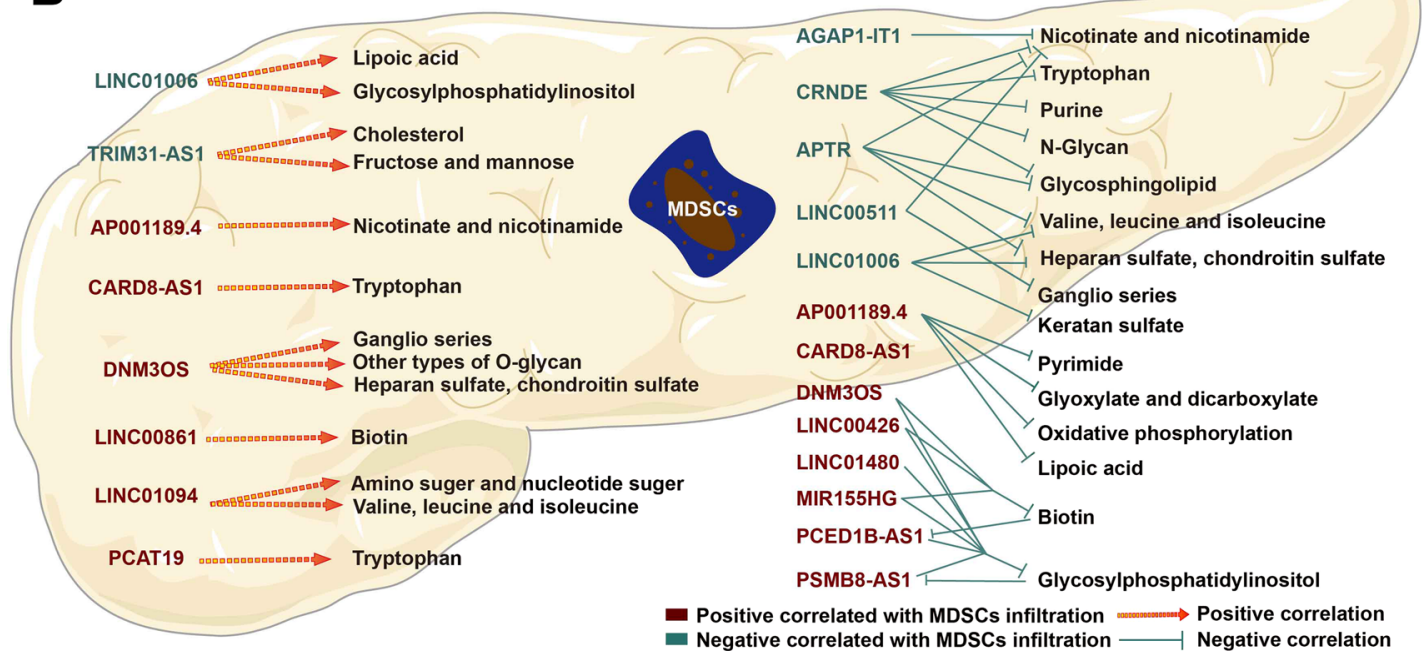

Fig. 3 The TIMELnc manual was constructed to identify IncRNAs that are simultaneously correlated with tumor metabolism and immune cell infiltration. a Flow chart. $\mathbf{b}$ LncRNAs that are simultaneously associated with MDSCs and various metabolic pathways in pancreatic cancer are shown as an example 
in Fig. 3a and constructed the TIMELnc manual. This manual consisted of two sections: one section lists 85 lncRNAs associated with metabolic pathways, while the other section presents lncRNAs related to the infiltration of 28 immune cell types. Notably, we set an extremely low threshold (Pearson's correlation coefficient $(r)<0.1$ ) to screen potential lncRNAs of interest; hence, readers are recommended to set a higher threshold (e.g., $r>0.4$ ) when using the manual if they want to select lncRNAs for further experimental validation.

We defined TIME-IncRNAs as those simultaneously correlated with intratumoral metabolic rewiring and immune cell infiltration. Readers could easily acquire mutually correlated metabolic pathway-lncRNAimmune signature pairs using the "screening" function in EXCEL. A representative screen of TIME-IncRNAs is described below. We set the threshold $(r>0.4)$ to screen metabolism-associated lncRNAs and immunity-associated lncRNAs in TCGA-PAAD cohort. An intersection was then acquired, and the metabolism-lncRNA-immunity network was established. We visualized the representative metabolism-lncRNA-MDSC correlation network in Fig. 3b. As shown in this figure, the lncRNA PCAT19 and CARD8-AS1 were positively associated with both tryptophan metabolism and MDSC infiltration, suggesting that their immunosuppressive role in the tumor microenvironment is potentially mediated by promoting immunosuppressive metabolism. Referring to the existing literature, PCAT19 is an oncogenic lncRNA that promotes tumor progression through multiple mechanisms [321-324], similar to CARD8-AS1 $[325,326]$. In this context, their experimentally validated oncogenic functions paralleled their immunosuppressive roles we proposed using the TIMELnc manual, which also supported the value of applying TIMELnc in designing future studies. Readers can download the TIMELnc manual in the Additional files 1 and 2.

\section{Conclusions}

Although more mechanisms underlying the intratumor interactions between metabolism and immune regulation have been deciphered in recent years, challenges and difficulties remain to be resolved before their effective "bedside" translation. One of the most important obstacles to metabolism-targeted treatment in cancers is that the activation of some so-called oncogenic pathways, such as anaerobic glycolysis, is also imperative for maintaining the antitumor function of effector immune cells [5, 327-329]. Under these circumstances, methods that precisely target metabolic pathways in tumor cells have become a bottleneck to the accelerated application of related regimens.
Our review summarizes existing knowledge of the role of noncoding RNAs in the remodeling of tumor metabolism and the immune microenvironment. Then, we proposed that noncoding RNAs potentially serve as hinges bridging metabolic activity and immune responses given their extensive action mechanisms based on motif recognition patterns. Target potential hub noncoding RNAs may simultaneously regulate multiple immunometabolic axes and reach optimal efficacy alone or in combination with immune checkpoint inhibitors. Hence, we also established the TIMELnc manual, which may help researchers screen these hub lncRNAs in future studies.

\section{Supplementary Information}

The online version contains supplementary material available at https://doi. org/10.1186/s13045-021-01179-y.

Additional file 1: The TimeLnc manual in 28 cancers (Part 1: METABOLISM).

Additional file 2: The TimeLnc manual in 28 cancers (Part 2: IMMUNITY)

\section{Acknowledgements}

Not applicable.

\section{Authors' contributions}

YYZ, QJM and QMX contributed to conceptualization and writing —original draft; YYZ and QJM provided methodology; ZZH, QMX and PC performed investigation; YRL, JY and JXC contributed to visualization; XXF, YYL and $\mathrm{HL}$ done supervision; $Y Y Z$ and $H L$ performed writing — review and editing. All authors read and approved the final manuscript.

\section{Funding}

This work was supported by National Key Research and Development Project (2017YFC0110802), Zhejiang province Key Research and Development Project (2020C01059), National Natural Science Foundation of China (81872297 and 81874059), Zhejiang Engineering Research Center of Cognitive Healthcare (2017E10011) and National Key Scientific Instrument and Equipment Development Project (81827804).

Availability of data and materials

The genelist of metabolic pathways was initially downloaded from KEGG (https://www.genome.jp/kegg/pathway.html), and the genelist to estimate immune cell infiltration in our study was based on a previously published study by Shao lab (PMID: 30837276).

\section{Declarations}

Ethics approval and consent to participate Not applicable.

\section{Consent for publication}

Not applicable.

\section{Competing interests}

The authors have no conflicts of interest to declare.

\section{Author details}

${ }^{1}$ Department of General Surgery, Sir Run Run Shaw Hospital, School of Medicine, Zhejiang University, Hangzhou 310016, China. ${ }^{2}$ State Key Laboratory of Modern Optical Instrumentations, Centre for Optical and Electromagnetic Research, College of Optical Science and Engineering, International Research Center for Advanced Photonics, Zhejiang University, Hangzhou 310058, China. 
${ }^{3}$ Zhejiang Engineering Research Center of Cognitive Healthcare, Sir Run Run Shaw Hospital, School of Medicine, Zhejiang University, Hangzhou 310016, China.

Received: 4 July 2021 Accepted: 27 September 2021 Published online: 15 October 2021

\section{References}

1. Eisenberg L, Eisenberg-Bord M, Eisenberg-Lerner A, Sagi-Eisenberg R. Metabolic alterations in the tumor microenvironment and their role in oncogenesis. Cancer Lett. 2020;484:65-71.

2. Li X, Wenes M, Romero P, Huang SC, Fendt SM, Ho PC. Navigating metabolic pathways to enhance antitumour immunity and immunotherapy. Nat Rev Clin Oncol. 2019;16(7):425-41.

3. Sun L, Suo C, Li ST, Zhang H, Gao P. Metabolic reprogramming for cancer cells and their microenvironment: beyond the Warburg effect. Biochim Biophys Acta. 2018;1870(1):51-66.

4. Wei F, Wang D, Wei J, Tang N, Tang L, Xiong F, Guo C, Zhou M, Li X, Li $G$, et al. Metabolic crosstalk in the tumor microenvironment regulates antitumor immunosuppression and immunotherapy resisitance. Cell Mol Life Sci CMLS. 2021;78(1):173-93.

5. Biswas SK. Metabolic reprogramming of immune cells in cancer progression. Immunity. 2015;43(3):435-49.

6. Akins NS, Nielson TC, Le HV. Inhibition of glycolysis and glutaminolysis: an emerging drug discovery approach to combat cancer. Curr Top Med Chem. 2018;18(6):494-504.

7. Vander Heiden MG, Cantley LC, Thompson CB. Understanding the Warburg effect: the metabolic requirements of cell proliferation. Science (New York, NY). 2009;324(5930):1029-33.

8. Hsu PP, Sabatini DM. Cancer cell metabolism: Warburg and beyond. Cell. 2008;134(5):703-7.

9. Pavlova NN, Thompson CB. The emerging hallmarks of cancer metabolism. Cell Metab. 2016;23(1):27-47.

10. Comito G, Iscaro A, Bacci M, Morandi A, Ippolito L, Parri M, Montagnani I, Raspollini MR, Serni S, Simeoni L, et al. Lactate modulates CD4(+) T-cell polarization and induces an immunosuppressive environment, which sustains prostate carcinoma progression via TLR8/miR21 axis. Oncogene. 2019;38(19):3681-95.

11. Husain Z, Huang Y, Seth P, Sukhatme VP. Tumor-derived lactate modifies antitumor immune response: effect on myeloid-derived suppressor cells and NK cells. J Immunol. 2013;191(3):1486-95.

12. Stone SC, Rossetti RAM, Alvarez KLF, Carvalho JP, Margarido PFR, Baracat EC, Tacla M, Boccardo E, Yokochi K, Lorenzi NP, et al. Lactate secreted by cervical cancer cells modulates macrophage phenotype. J Leukoc Biol. 2019;105(5):1041-54.

13. Zhang W, Wang G, Xu ZG, Tu H, Hu F, Dai J, Chang Y, Chen Y, Lu Y, Zeng $\mathrm{H}$, et al. Lactate is a natural suppressor of RLR signaling by targeting MAVS. Cell. 2019:178(1):176-189.e115.

14. Watson MJ, Vignali PDA, Mullett SJ, Overacre-Delgoffe AE, Peralta RM, Grebinoski S, Menk AV, Rittenhouse NL, DePeaux K, Whetstone RD, et al. Metabolic support of tumour-infiltrating regulatory $T$ cells by lactic acid. Nature. 2021;591:645-51.

15. Vijayan D, Young A, Teng MWL, Smyth MJ. Targeting immunosuppressive adenosine in cancer. Nat Rev Cancer. 2017;17(12):709-24.

16. Lv H, Lv G, Chen C, Zong Q, Jiang G, Ye D, Cui X, He Y, Xiang W, Han Q, et al. $\mathrm{NAD}(+)$ metabolism maintains inducible PD-L1 expression to drive tumor immune evasion. Cell Metab. 2021;33(1):110-127.e115.

17. Patsoukis N, Bardhan K, Chatterjee P, Sari D, Liu B, Bell LN, Karoly ED, Freeman GJ, Petkova V, Seth P, et al. PD-1 alters T-cell metabolic reprogramming by inhibiting glycolysis and promoting lipolysis and fatty acid oxidation. Nat Commun. 2015;6:6692.

18. Wang W, Green M, Choi JE, Gijón M, Kennedy PD, Johnson JK, Liao P, Lang X, Kryczek I, Sell A, et al. CD8(+) T cells regulate tumour ferroptosis during cancer immunotherapy. Nature. 2019:569(7755):270-4.

19. Dröge W, Eck HP, Gmünder H, Mihm S. Modulation of lymphocyte functions and immune responses by cysteine and cysteine derivatives. Am J Med. 1991;91(3c):140s-4s.
20. Srivastava MK, Sinha P, Clements VK, Rodriguez P, Ostrand-Rosenberg S. Myeloid-derived suppressor cells inhibit T-cell activation by depleting cystine and cysteine. Can Res. 2010;70(1):68-77.

21. Kumar V, Patel S, Tcyganov E, Gabrilovich DI. The nature of myeloidderived suppressor cells in the tumor microenvironment. Trends Immunol. 2016;37(3):208-20.

22. Kim J, Bae JS. Tumor-associated macrophages and neutrophils in tumor microenvironment. Mediators Inflamm. 2016;2016:6058147.

23. Gabrilovich DI, Nagaraj S. Myeloid-derived suppressor cells as regulators of the immune system. Nat Rev Immunol. 2009;9(3):162-74.

24. Baumann T, Dunkel A, Schmid C, Schmitt S, Hiltensperger M, Lohr K, Laketa V, Donakonda S, Ahting U, Lorenz-Depiereux B, et al. Regulatory myeloid cells paralyze T cells through cell-cell transfer of the metabolite methylglyoxal. Nat Immunol. 2020;21(5):555-66.

25. Anastasiadou E, Jacob LS, Slack FJ. Non-coding RNA networks in cancer Nat Rev Cancer. 2018:18(1):5-18.

26. Esteller M. Non-coding RNAs in human disease. Nat Rev Genet. 2011;12(12):861-74.

27. Slack FJ, Chinnaiyan AM. The role of non-coding RNAs in oncology. Cell. 2019:179(5):1033-55.

28. Qi X, Zhang DH, Wu N, Xiao JH, Wang X, Ma W. ceRNA in cancer: possible functions and clinical implications. J Med Genet. 2015;52(10):710-8.

29. Tay Y, Rinn J, Pandolfi PP. The multilayered complexity of ceRNA crosstalk and competition. Nature. 2014;505(7483):344-52.

30. Adams BD, Parsons C, Walker L, Zhang WC, Slack FJ. Targeting noncoding RNAs in disease. J Clin Investig. 2017;127(3):761-71.

31. Karreth FA, Pandolfi PP. ceRNA cross-talk in cancer: when ce-bling rivalries go awry. Cancer Discov. 2013;3(10):1113-21.

32. Tan X, Wang P, Lou J, Zhao J. Knockdown of IncRNA NEAT1 suppresses hypoxia-induced migration, invasion and glycolysis in anaplastic thyroid carcinoma cells through regulation of miR-206 and miR-599. Cancer Cell Int. 2020;20:132

33. Zhang W, Mao S, Shi D, Zhang J, Zhang Z, Guo Y, Wu Y, Wang R, Wang L, Huang $Y$, et al. MicroRNA-153 decreases tryptophan catabolism and inhibits angiogenesis in bladder cancer by targeting indoleamine 2,3-dioxygenase 1. Front Oncol. 2019:9:619.

34. Shao Y, Chen HT, Ma QR, Zhang YW, He YQ, Liu J. Long non-coding RNA PVT1 regulates glioma proliferation, invasion, and aerobic glycolysis via miR-140-5p. Eur Rev Med Pharmacol Sci. 2020;24(1):274-83.

35. Hanniford D, Ulloa-Morales A, Karz A, Berzoti-Coelho MG, Moubarak RS, Sánchez-Sendra B, Kloetgen A, Davalos V, Imig J, Wu P, et al. Epigenetic silencing of CDR1as drives IGF2BP3-mediated melanoma invasion and metastasis. Cancer Cell. 2020;37(1):55-70.e15.

36. Liu J, Liu H, Zeng Q, Xu P, Liu M, Yang N. Circular RNA circ-MAT2B facilitates glycolysis and growth of gastric cancer through regulating the miR-515-5p/HIF-1a axis. Cancer Cell Int. 2020;20:171.

37. Lou Q, Liu R, Yang X, Li W, Huang L, Wei L, Tan H, Xiang N, Chan K, Chen $J$, et al. miR-448 targets IDO1 and regulates CD8(+) T cell response in human colon cancer. J Immunother Cancer. 2019;7(1):210.

38. Huang Q, Xia J, Wang L, Wang X, Ma X, Deng Q, Lu Y, Kumar M, Zhou Z, Li L, et al. miR-153 suppresses IDO1 expression and enhances CART cell immunotherapy. J Hematol Oncol. 2018;11(1):58.

39. Zhang J, Han X, Hu X, Jin F, Gao Z, Yin L, Qin J, Yin F, Li C, Wang Y. IDO1 impairs NK cell cytotoxicity by decreasing NKG2D/NKG2DLs via promoting miR-18a. Mol Immunol. 2018;103:144-55.

40. Coelho-Lima J, Spyridopoulos I. Non-coding RNA regulation of T cell biology: implications for age-associated cardiovascular diseases. Exp Gerontol. 2018;109:38-46.

41. Uthaya Kumar DB, Williams A. Long non-coding RNAs in immune regulation and their potential as therapeutic targets. Int Immunopharmacol. 2020;81:106279.

42. Wells AC, Pobezinskaya EL, Pobezinsky LA. Non-coding RNAs in CD8 T cell biology. Mol Immunol. 2020;120:67-73.

43. Koppenol WH, Bounds PL, Dang CV. Otto Warburg's contributions to current concepts of cancer metabolism. Nat Rev Cancer. 2011;11(5):325-37.

44. Pascale RM, Calvisi DF, Simile MM, Feo CF, Feo F. The Warburg effect 97 years after its discovery. Cancers Basel. 2020;12(10):2819.

45. García-Cañaveras JC, Chen L, Rabinowitz JD. The tumor metabolic microenvironment: lessons from lactate. Cancer Res. 2019:79(13):3155-62. 
46. Hirschhaeuser F, Sattler UG, Mueller-Klieser W. Lactate: a metabolic key player in cancer. Cancer Res. 2011;71(22):6921-5.

47. Renner K, Bruss C, Schnell A, Koehl G, Becker HM, Fante M, Menevse AN, Kauer N, Blazquez R, Hacker L, et al. Restricting glycolysis preserves $T$ cell effector functions and augments checkpoint therapy. Cell Rep. 2019;29(1):135-150.e139.

48. Feng J, Yang $H$, Zhang $Y$, Wei $H$, Zhu Z, Zhu B, Yang M, Cao W, Wang L, Wu Z. Tumor cell-derived lactate induces TAZ-dependent upregulation of PD-L1 through GPR81 in human lung cancer cells. Oncogene. 2017;36(42):5829-39.

49. Balar AV, Weber JS. PD-1 and PD-L1 antibodies in cancer: current status and future directions. Cancer Immunol Immunother CII. 2017;66(5):551-64.

50. Wang X, Guo G, Guan H, Yu Y, Lu J, Yu J. Challenges and potential of PD-1/PD-L1 checkpoint blockade immunotherapy for glioblastoma. J Exp Clin Cancer Res CR. 2019;38(1):87.

51. Nilsson A, Haanstra JR, Engqvist M, Gerding A, Bakker BM, Klingmüller $U$, Teusink B, Nielsen J. Quantitative analysis of amino acid metabolism in liver cancer links glutamate excretion to nucleotide synthesis. Proc Natl Acad Sci U S A. 2020:117(19):10294-304.

52. Sikalidis AK. Amino acids and immune response: a role for cysteine, glutamine, phenylalanine, tryptophan and arginine in T-cell function and cancer? Pathology oncology research : POR. 2015;21(1):9-17.

53. Arensman MD, Yang XS, Leahy DM, Toral-Barza L, Mileski M, Rosfiord EC, Wang F, Deng S, Myers JS, Abraham RT, et al. Cystine-glutamate antiporter $\mathrm{XCT}$ deficiency suppresses tumor growth while preserving antitumor immunity. Proc Natl Acad Sci USA. 2019:116(19):9533-42.

54. Leone RD, Zhao L, Englert JM, Sun IM, Oh MH, Sun IH, Arwood ML, Bettencourt IA, Patel $\mathrm{CH}$, Wen J, et al. Glutamine blockade induces divergent metabolic programs to overcome tumor immune evasion. Science. 2019:366(6468):1013-21.

55. Wang Q, Liu D, Song P, Zou MH. Tryptophan-kynurenine pathway is dysregulated in inflammation, and immune activation. Front Biosci Landmark Edn. 2015;20:1116-43.

56. Liu Y, Liang X, Dong W, Fang Y, Lv J, Zhang T, Fiskesund R, Xie J, Liu $J$, Yin $X$, et al. Tumor-repopulating cells induce PD-1 expression in $\mathrm{CD} 8(+) T$ cells by transferring kynurenine and AhR activation. Cancer Cell. 2018:33(3):480-494.e487.

57. Mezrich JD, Fechner JH, Zhang X, Johnson BP, Burlingham WJ, Bradfield CA. An interaction between kynurenine and the aryl hydrocarbon receptor can generate regulatory T cells. J Immunol. 2010;185(6):3190-8.

58. Triplett TA, Garrison KC, Marshall N, Donkor M, Blazeck J, Lamb C, Qerqez A, Dekker JD, Tanno Y, Lu WC, et al. Reversal of indoleamine 2,3-dioxygenase-mediated cancer immune suppression by systemic kynurenine depletion with a therapeutic enzyme. Nat Biotechnol. 2018;36(8):758-64

59. Young A, Ngiow SF, Gao Y, Patch AM, Barkauskas DS, Messaoudene M, Lin G, Coudert JD, Stannard KA, Zitvogel L, et al. A2AR adenosine signaling suppresses natural killer cell maturation in the tumor microenvironment. Cancer Res. 2018;78(4):1003-16.

60. Kjaergaard J, Hatfield S, Jones G, Ohta A, Sitkovsky M. A(2A) adenosine receptor gene deletion or synthetic $\mathrm{A}(2 \mathrm{~A})$ antagonist liberate tumor-reactive CD8(+) T cells from tumor-induced immunosuppression. J Immunol. 2018;201(2):782-91.

61. Leone RD, Sun IM, Oh MH, Sun IH, Wen J, Englert J, Powell JD. Inhibition of the adenosine A2a receptor modulates expression of $\mathrm{T}$ cell coinhibitory receptors and improves effector function for enhanced checkpoint blockade and ACT in murine cancer models. Cancer Immunol Immunother CII. 2018:67(8):1271-84.

62. Ma SR, Deng WW, Liu JF, Mao L, Yu GT, Bu LL, Kulkarni AB, Zhang WF, Sun ZJ. Blockade of adenosine A2A receptor enhances CD8(+) $T$ cells response and decreases regulatory $T$ cells in head and neck squamous cell carcinoma. Mol Cancer. 2017;16(1):99.

63. Yu F, Zhu C, Xie $Q$, Wang Y. Adenosine $A(2 A)$ receptor antagonists for cancer immunotherapy. J Med Chem. 2020;63(21):12196-212.

64. Walker W, Rotondo D. Prostaglandin E2 is a potent regulator of interleukin-12- and interleukin-18-induced natural killer cell interferongamma synthesis. Immunology. 2004;111(3):298-305.
65. Joshi PC, Zhou X, Cuchens M, Jones Q. Prostaglandin E2 suppressed IL-15-mediated human NK cell function through down-regulation of common gamma-chain. J Immunol. 2001;166(2):885-91.

66. Mailliard RB, Alber SM, Shen H, Watkins SC, Kirkwood JM, Herberman RB, Kalinski P. IL-18-induced CD83+CCR7+ NK helper cells. J Exp Med. 2005;202(7):941-53

67. Heusinkveld M, de Vos van Steenwijk PJ, Goedemans R, Ramwadhdoebe TH, Gorter A, Welters MJ, van Hall T, van der Burg SH. M2 macrophages induced by prostaglandin E2 and IL-6 from cervical carcinoma are switched to activated $\mathrm{M} 1$ macrophages by $\mathrm{CD} 4+$ Th1 cells. J Immunol. 2011;187(3):1157-65.

68. Sharma S, Stolina M, Yang SC, Baratelli F, Lin JF, Atianzar K, Luo J, Zhu L, Lin $Y$, Huang $M$, et al. Tumor cyclooxygenase 2-dependent suppression of dendritic cell function. Clin Cancer Res. 2003;9(3):961-8.

69. Obermajer N, Muthuswamy R, Lesnock J, Edwards RP, Kalinski P. Positive feedback between PGE2 and COX2 redirects the differentiation of human dendritic cells toward stable myeloid-derived suppressor cells. Blood. 2011;118(20):5498-505.

70. Specht C, Bexten S, Kölsch E, Pauels HG. Prostaglandins, but not tumor-derived IL-10, shut down concomitant tumor-specific CTL responses during murine plasmacytoma progression. Int I Cancer. 2001;91(5):705-12.

71. Valitutti S, Dessing M, Lanzavecchia A. Role of CAMP in regulating cytotoxic T lymphocyte adhesion and motility. Eur J Immunol. 1993;23(4):790-5.

72. Simkin NJ, Jelinek DF, Lipsky PE. Inhibition of human B cell responsiveness by prostaglandin E2. J Immunol. 1987;138(4):1074-81.

73. Betz M, Fox BS. Prostaglandin E2 inhibits production of Th1 lymphokines but not of Th2 lymphokines. J Immunol. 1991;146(1):108-13.

74. Khayrullina T, Yen JH, Jing H, Ganea D. In vitro differentiation of dendritic cells in the presence of prostaglandin E2 alters the IL-12/ IL-23 balance and promotes differentiation of Th17 cells. J Immunol. 2008;181(1):721-35.

75. Porta C, Consonni FM, Morlacchi S, Sangaletti S, Bleve A, Totaro MG, Larghi P, Rimoldi M, Tripodo C, Strauss L, et al. Tumor-derived prostaglandin E2 promotes $\mathrm{p} 50 \mathrm{NF}-\mathrm{kB}$-dependent differentiation of monocytic MDSCs. Cancer Res. 2020;80(13):2874-88.

76. Gutiérrez S, Svahn SL, Johansson ME. Effects of omega-3 fatty acids on immune cells. Int J Mol Sci. 2019;20(20):5028.

77. Lochner M, Berod L, Sparwasser T. Fatty acid metabolism in the regulation of T cell function. Trends Immunol. 2015;36(2):81-91.

78. Namgaladze D, Brüne B. Macrophage fatty acid oxidation and its roles in macrophage polarization and fatty acid-induced inflammation. Biochim Biophys Acta. 2016;1861(11):1796-807.

79. Raud B, McGuire PJ, Jones RG, Sparwasser T, Berod L. Fatty acid metabolism in CD8(+) T cell memory: challenging current concepts. Immunol Rev. 2018;283(1):213-31.

80. Tiwary S, Berzofsky JA, Terabe M. Altered lipid tumor environment and its potential effects on NKT cell function in tumor immunity. Front Immunol. 2019;10:2187.

81. Tyrakis PA, Palazon A, Macias D, Lee KL, Phan AT, Veliça P, You J, Chia GS, Sim J, Doedens A, et al. S-2-hydroxyglutarate regulates CD8(+) T-lymphocyte fate. Nature. 2016;540(7632):236-41.

82. Bunse L, Pusch S, Bunse T, Sahm F, Sanghvi K, Friedrich M, Alansary D, Sonner JK, Green E, Deumelandt K, et al. Suppression of antitumor T cell immunity by the oncometabolite (R)-2-hydroxyglutarate. Nat Med. 2018;24(8):1192-203.

83. Rodríguez PC, Ochoa AC. Arginine regulation by myeloid derived suppressor cells and tolerance in cancer: mechanisms and therapeutic perspectives. Immunol Rev. 2008;222:180-91.

84. Rodriguez PC, Quiceno DG, Zabaleta J, Ortiz B, Zea AH, Piazuelo MB, Delgado A, Correa P, Brayer J, Sotomayor EM, et al. Arginase I production in the tumor microenvironment by mature myeloid cells inhibits T-cell receptor expression and antigen-specific T-cell responses. Cancer Res. 2004;64(16):5839-49.

85. Sun K, Tang S, Hou Y, Xi L, Chen Y, Yin J, Peng M, Zhao M, Cui X, Liu M. Oxidized ATM-mediated glycolysis enhancement in breast cancerassociated fibroblasts contributes to tumor invasion through lactate as metabolic coupling. EBioMedicine. 2019;41:370-83.

86. Ippolito L, Morandi A, Taddei ML, Parri M, Comito G, Iscaro A, Raspollini MR, Magherini F, Rapizzi E, Masquelier J, et al. Cancer-associated 
fibroblasts promote prostate cancer malignancy via metabolic rewiring and mitochondrial transfer. Oncogene. 2019;38(27):5339-55.

87. Comito G, Ippolito L, Chiarugi P, Cirri P. Nutritional exchanges within tumor microenvironment: impact for cancer aggressiveness. Front Oncol. 2020;10:396.

88. Yang L, Achreja A, Yeung TL, Mangala LS, Jiang D, Han C, Baddour J, Marini JC, Ni J, Nakahara R, et al. Targeting stromal glutamine synthetase in tumors disrupts tumor microenvironment-regulated cancer cell growth. Cell Metab. 2016;24(5):685-700.

89. Tardito S, Oudin A, Ahmed SU, Fack F, Keunen O, Zheng L, Miletic H, Sakariassen P, Weinstock A, Wagner A, et al. Glutamine synthetase activity fuels nucleotide biosynthesis and supports growth of glutaminerestricted glioblastoma. Nat Cell Biol. 2015;17(12):1556-68.

90. Meyer KA, Neeley CK, Baker NA, Washabaugh AR, Flesher CG, Nelson BS, Frankel TL, Lumeng CN, Lyssiotis CA, Wynn ML, et al. Adipocytes promote pancreatic cancer cell proliferation via glutamine transfer. Biochem Biophys Rep. 2016;7:144-9.

91. Zhang D, Tang Z, Huang H, Zhou G, Cui C, Weng Y, Liu W, Kim S, Lee S, Perez-Neut M, et al. Metabolic regulation of gene expression by histone lactylation. Nature. 2019;574(7779):575-80

92. Enzo E, Santinon G, Pocaterra A, Aragona M, Bresolin S, Forcato M, Grifoni D, Pession A, Zanconato F, Guzzo G, et al. Aerobic glycolysis tunes YAP/TAZ transcriptional activity. EMBO J. 2015;34(10):1349-70.

93. Moussaieff A, Rouleau M, Kitsberg D, Cohen M, Levy G, Barasch D, Nemirovski A, Shen-Orr S, Laevsky I, Amit M, et al. Glycolysis-mediated changes in acetyl-COA and histone acetylation control the early differentiation of embryonic stem cells. Cell Metab. 2015;21(3):392-402.

94. Li W, Tanikawa T, Kryczek I, Xia H, Li G, Wu K, Wei S, Zhao L, Vatan L, Wen $B$, et al. Aerobic glycolysis controls myeloid-derived suppressor cells and tumor immunity via a specific CEBPB isoform in triple-negative breast cancer. Cell Metab. 2018;28(1):87-103.e106.

95. Munn DH, Sharma MD, Baban B, Harding HP, Zhang Y, Ron D, Mellor AL. GCN2 kinase in T cells mediates proliferative arrest and anergy induction in response to indoleamine 2,3-dioxygenase. Immunity. 2005;22(5):633-42.

96. Hermans D, Gautam S, García-Cañaveras JC, Gromer D, Mitra S, Spolski $\mathrm{R}$, Li P, Christensen S, Nguyen R, Lin JX, et al. Lactate dehydrogenase inhibition synergizes with IL-21 to promote CD8(+) T cell stemness and antitumor immunity. Proc Natl Acad Sci USA. 2020;117(11):6047-55.

97. Zhang C, Yue C, Herrmann A, Song J, Egelston C, Wang T, Zhang Z, Li W, Lee $\mathrm{H}$, Aftabizadeh M, et al. STAT3 activation-induced fatty acid oxidation in CD8(+) T effector cells is critical for obesity-promoted breast tumor growth. Cell Metab. 2020;31(1):148-161.e145.

98. Hossain F, Al-Khami AA, Wyczechowska D, Hernandez C, Zheng L, Reiss K, Valle LD, Trillo-Tinoco J, Maj T, Zou W, et al. Inhibition of fatty acid oxidation modulates immunosuppressive functions of myeloid-derived suppressor cells and enhances cancer therapies. Cancer Immunol Res. 2015;3(11):1236-47.

99. Gómez V, Eykyn TR, Mustapha R, Flores-Borja F, Male V, Barber PR, Patsialou A, Green R, Panagaki F, Li CW, et al. Breast cancer-associated macrophages promote tumorigenesis by suppressing succinate dehydrogenase in tumor cells. Sci Signal. 2020;13(652):eaax4585.

100. Noman MZ, Desantis G, Janji B, Hasmim M, Karray S, Dessen P, Bronte V, Chouaib S. PD-L1 is a novel direct target of HIF-1a, and its blockade under hypoxia enhanced MDSC-mediated T cell activation. J Exp Med. 2014;211(5):781-90

101. Jeong H, Kim S, Hong BJ, Lee CJ, Kim YE, Bok S, Oh JM, Gwak SH, Yoo MY, Lee MS, et al. Tumor-associated macrophages enhance tumor hypoxia and aerobic glycolysis. Cancer Res. 2019;79(4):795-806.

102. Romano G, Veneziano D, Acunzo M, Croce CM. Small non-coding RNA and cancer. Carcinogenesis. 2017;38(5):485-91.

103. Yang JX, Rastetter RH, Wilhelm D. Non-coding RNAs: an introduction. Adv Exp Med Biol. 2016;886:13-32.

104. Fabian MR, Sonenberg N, Filipowicz W. Regulation of mRNA translation and stability by microRNAs. Annu Rev Biochem. 2010;79:351-79.

105. Du WW, Zhang C, Yang W, Yong T, Awan FM, Yang BB. Identifying and characterizing circRNA-protein interaction. Theranostics. 2017;7(17):4183-91

106. Dykes IM, Emanueli C. Transcriptional and post-transcriptional gene regulation by long non-coding RNA. Genomics Proteomics Bioinform. 2017;15(3):177-86.
107. Zheng X, Chen L, Zhou Y, Wang Q, Zheng Z, Xu B, Wu C, Zhou Q, Hu W, Wu C, et al. A novel protein encoded by a circular RNA circPPP1R12A promotes tumor pathogenesis and metastasis of colon cancer via Hippo-YAP signaling. Mol Cancer. 2019;18(1):47.

108. Pang Y, Liu Z, Han H, Wang B, Li W, Mao C, Liu S. Peptide SMIM30 promotes HCC development by inducing SRC/YES1 membrane anchoring and MAPK pathway activation. J Hepatol. 2020;73(5):1155-69.

109. Wu P, Mo Y, Peng M, Tang T, Zhong Y, Deng X, Xiong F, Guo C, Wu X, Li Y, et al. Emerging role of tumor-related functional peptides encoded by IncRNA and circRNA. Mol Cancer. 2020;19(1):22.

110. Li JH, Liu S, Zhou H, Qu LH, Yang JH. starBase v2.0: decoding miRNAceRNA, miRNA-ncRNA and protein-RNA interaction networks from large-scale CLIP-Seq data. Nucl Acids Res. 2014;42:D92-7.

111. Li X, Ding J, Wang X, Cheng Z, Zhu Q. NUDT21 regulates circRNA cyclization and ceRNA crosstalk in hepatocellular carcinoma. Oncogene. 2020;39(4):891-904.

112. Zhu J, Zhang X, Gao W, Hu H, Wang X, Hao D. IncRNA/circRNA-miRNAmRNA ceRNA network in lumbar intervertebral disc degeneration. Mol Med Rep. 2019;20(4):3160-74.

113. Luo Z, Rong Z, Zhang J, Zhu Z, Yu Z, Li T, Fu Z, Qiu Z, Huang C. Circular RNA circCCDC9 acts as a miR-6792-3p sponge to suppress the progression of gastric cancer through regulating CAV1 expression. Mol Cancer. 2020;19(1):86

114. Zhu Z, Rong Z, Luo Z, Yu Z, Zhang J, Qiu Z, Huang C. Circular RNA circNHSL1 promotes gastric cancer progression through the miR-1306-3p/ SIX1/vimentin axis. Mol Cancer. 2019;18(1):126.

115. Meister G, Tuschl T. Mechanisms of gene silencing by double-stranded RNA. Nature. 2004;431(7006):343-9.

116. Abdollahzadeh R, Daraei A, Mansoori Y, Sepahvand M, Amoli MM, Tavakkoly-Bazzaz J. Competing endogenous RNA (ceRNA) cross talk and language in ceRNA regulatory networks: a new look at hallmarks of breast cancer. J Cell Physiol. 2019;234(7):10080-100.

117. Wang R, Zhang S, Chen X, Li N, Li J, Jia R, Pan Y, Liang H. ElF4A3-induced circular RNA MMP9 (circMMP9) acts as a sponge of miR-124 and promotes glioblastoma multiforme cell tumorigenesis. Mol Cancer. 2018;17(1):166

118. Wei $Y$, Chen $X$, Liang $C$, Ling $Y$, Yang $X$, Ye $X$, Zhang $H$, Yang $P$, Cui $X$, Ren $Y$, et al. A noncoding regulatory RNAs network driven by circ-CDYL acts specifically in the early stages hepatocellular carcinoma. Hepatology. 2020;71(1):130-47.

119. Liu H, Deng H, Zhao Y, Li C, Liang Y. LncRNA XIST/miR-34a axis modulates the cell proliferation and tumor growth of thyroid cancer through MET-PI3K-AKT signaling. J Exp Clin Cancer Res CR. 2018;37(1):279.

120. Luo H, Xu C, Le W, Ge B, Wang T. IncRNA CASC11 promotes cancer cell proliferation in bladder cancer through miRNA-150. J Cell Biochem. 2019:120(8):13487-93.

121. Zhao W, Geng D, Li S, Chen Z, Sun M. LncRNA HOTAIR influences cell growth, migration, invasion, and apoptosis via the miR-20a-5p/HMGA2 axis in breast cancer. Cancer Med. 2018;7(3):842-55.

122. Chen D, Ma W, Ke Z, Xie F. CircRNA hsa_circ_100395 regulates miR1228/TCF21 pathway to inhibit lung cancer progression. Cell Cycle. 2018;17(16):2080-90.

123. Liu Z, Yu Y, Huang Z, Kong Y, Hu X, Xiao W, Quan J, Fan X. CircRNA-5692 inhibits the progression of hepatocellular carcinoma by sponging miR328-5p to enhance DAB2IP expression. Cell Death Dis. 2019;10(12):900.

124. Sang Y, Chen B, Song X, Li Y, Liang Y, Han D, Zhang N, Zhang H, Liu Y, Chen T, et al. circRNA_0025202 regulates tamoxifen sensitivity and tumor progression via regulating the miR-182-5p/FOXO3a Axis in breast cancer. Mol Therapy. 2019;27(9):1638-52.

125. Liang H, Yu T, Han Y, Jiang H, Wang C, You T, Zhao X, Shan H, Yang R, Yang $L$, et al. LncRNA PTAR promotes EMT and invasion-metastasis in serous ovarian cancer by competitively binding miR-101-3p to regulate ZEB1 expression. Mol Cancer. 2018;17(1):119.

126. Pan J, Fang S, Tian H, Zhou C, Zhao X, Tian H, He J, Shen W, Meng X, Jin $X$, et al. IncRNA JPX/miR-33a-5p/Twist1 axis regulates tumorigenesis and metastasis of lung cancer by activating $\mathrm{Wnt} / \mathrm{B}$-catenin signaling. Mol Cancer. 2020;19(1):9.

127. Wang $H$, Huo $X$, Yang XR, He J, Cheng L, Wang N, Deng $X$, Jin H, Wang $\mathrm{N}$, Wang $\mathrm{C}$, et al. STAT3-mediated upregulation of IncRNA HOXD-AS1 as a ceRNA facilitates liver cancer metastasis by regulating SOX4. Mol Cancer. 2017;16(1):136. 
128. Han P, Li JW, Zhang BM, Lv JC, Li YM, Gu XY, Yu ZW, Jia YH, Bai XF, Li L, et al. The IncRNA CRNDE promotes colorectal cancer cell proliferation and chemoresistance via miR-181a-5p-mediated regulation of $\mathrm{Wnt} / \mathrm{\beta}$ catenin signaling. Mol Cancer. 2017;16(1):9.

129. Ren J, Ding L, Zhang D, Shi G, Xu Q, Shen S, Wang Y, Wang T, Hou Y. Carcinoma-associated fibroblasts promote the stemness and chemoresistance of colorectal cancer by transferring exosomal IncRNA H19. Theranostics. 2018;8(14):3932-48.

130. Zhu KP, Zhang CL, Ma XL, Hu JP, Cai T, Zhang L. Analyzing the Interactions of mRNAs and ncRNAs to predict competing endogenous RNA networks in osteosarcoma chemo-resistance. Mol Therapy. 2019;27(3):518-30.

131. Li Z, Qin X, Bian W, LiY, Shan B, Yao Z, Li S. Exosomal IncRNA ZFAS1 regulates esophageal squamous cell carcinoma cell proliferation, invasion, migration and apoptosis via microRNA-124/STAT3 axis. J Exp Clin Cancer Res CR. 2019;38(1):477.

132. Zhang X, Yao J, Shi H, Gao B, Zhang L. LncRNA TINCR/microRNA-107/ CD36 regulates cell proliferation and apoptosis in colorectal cancer via PPAR signaling pathway based on bioinformatics analysis. Biol Chem. 2019:400(5):663-75.

133. Hong W, Xue M, Jiang J, Zhang Y, Gao X. Circular RNA circ-CPA4/ let-7 miRNA/PD-L1 axis regulates cell growth, stemness, drug resistance and immune evasion in non-small cell lung cancer (NSCLC). J Exp Clin Cancer Res CR. 2020;39(1):149

134. Lu G, Li Y, Ma Y, Lu J, Chen Y, Jiang Q, Qin Q, Zhao L, Huang Q, Luo Z, et al. Long noncoding RNA LINC00511 contributes to breast cancer tumourigenesis and stemness by inducing the miR-185-3p/E2F1/ Nanog axis. J Exp Clin Cancer Res CR. 2018;37(1):289.

135. Wu H, Liu B, Chen Z, Li G, Zhang Z. MSC-induced IncRNA HCP5 drove fatty acid oxidation through miR-3619-5p/AMPK/PGC1a/CEBPB axis to promote stemness and chemo-resistance of gastric cancer. Cell Death Dis. 2020;11(4):233.

136. Bi J, Liu H, Cai Z, Dong W, Jiang N, Yang M, Huang J, Lin T. Circ-BPTF promotes bladder cancer progression and recurrence through the miR31-5p/RAB27A axis. Aging. 2018;10(8):1964-76.

137. Bi J, Liu H, Dong W, Xie W, He Q, Cai Z, Huang J, Lin T. Circular RNA circZKSCAN1 inhibits bladder cancer progression through miR-1178-3p/ p21 axis and acts as a prognostic factor of recurrence. Mol Cancer. 2019;18(1):133.

138. Xu R, Feng F, Yu X, Liu Z, Lao L. LncRNA SNHG4 promotes tumour growth by sponging miR-224-3p and predicts poor survival and recurrence in human osteosarcoma. Cell Proliferation. 2018:51(6):e12515.

139. Hua Q, Jin M, Mi B, Xu F, Li T, Zhao L, Liu J, Huang G. LINC01123, a C-Mycactivated long non-coding RNA, promotes proliferation and aerobic glycolysis of non-small cell lung cancer through miR-199a-5p/c-Myc axis. J Hematol Oncol. 2019;12(1):91.

140. Shi J, Zhang Y, Qin B, Wang Y, Zhu X. Long non-coding RNA LINC00174 promotes glycolysis and tumor progression by regulating miR-152-3p/ SLC2A1 axis in glioma. J Exp Clin Cancer Res CR. 2019;38(1):395.

141. Wang $X$, Zhang H, Yang H, Bai M, Ning T, Deng T, Liu R, Fan Q, Zhu K, $\mathrm{Li}$ J, et al. Exosome-delivered circRNA promotes glycolysis to induce chemoresistance through the miR-122-PKM2 axis in colorectal cancer. Mol Oncol. 2020;14(3):539-55.

142. Fong MY, Yan W, Ghassemian M, Wu X, Zhou X, Cao M, Jiang L, Wang J, Liu X, Zhang J, et al. Cancer-secreted miRNAs regulate amino-acidinduced $\mathrm{MTORC} 1$ signaling and fibroblast protein synthesis. EMBO Rep. 2021;22(2):e51239.

143. Monaco F, Gaetani S, Alessandrini F, Tagliabracci A, Bracci M, Valentino M, Neuzil J, Amati M, Bovenzi M, Tomasetti M, et al. Exosomal transfer of miR-126 promotes the anti-tumour response in malignant mesothelioma: role of miR-126 in cancer-stroma communication. Cancer Lett. 2019:463:27-36

144. Lin X, Yang F, Qi X, Li Q, Wang D, Yi T, Yin R, Zhao X, Zhong X, Bian C. LnCRNA DANCR promotes tumor growth and angiogenesis in ovarian cancer through direct targeting of miR-145. Mol Carcinog. 2019;58(12):2286-96.

145. Liu ZZ, Tian YF, Wu H, Ouyang SY, Kuang WL. LncRNA H1 9 promotes glioma angiogenesis through miR-138/HIF-1 a/VEGF axis. Neoplasma. 2020;67(1):111-8.

146. Zhang JX, Chen ZH, Chen DL, Tian XP, Wang CY, Zhou ZW, Gao Y, Xu Y, Chen C, Zheng ZS, et al. LINC01410-miR-532-NCF2-NF-kB feedback loop promotes gastric cancer angiogenesis and metastasis. Oncogene. 2018;37(20):2660-75.

147. Wang QM, Lian GY, Song Y, Huang YF, Gong Y. LncRNA MALAT1 promotes tumorigenesis and immune escape of diffuse large B cell lymphoma by sponging miR-195. Life Sci. 2019;231:116335.

148. Wei CY, Zhu MX, Lu NH, Liu JQ, Yang YW, Zhang Y, Shi YD, Feng ZH, Li JX, Qi FZ, et al. Circular RNA circ 0020710 drives tumor progression and immune evasion by regulating the miR-370-3p/CXCL12 axis in melanoma. Mol Cancer. 2020;19(1):84.

149. Zhang M, Wang N, Song P, Fu Y, Ren Y, Li Z, Wang J. LncRNA GATA3-AS1 facilitates tumour progression and immune escape in triple-negative breast cancer through destabilization of GATA3 but stabilization of PD-L1. Cell Proliferation. 2020;53(9):e12855.

150. Zhao L, Liu Y, Zhang J, Liu Y, Qi Q. LncRNA SNHG14/miR-5590-3p/ ZEB1 positive feedback loop promoted diffuse large B cell lymphoma progression and immune evasion through regulating PD-1/PD-L1 checkpoint. Cell Death Dis. 2019;10(10):731.

151. Li Z, Huang C, Bao C, Chen L, Lin M, Wang X, Zhong G, Yu B, Hu W, Dai $L$, et al. Exon-intron circular RNAs regulate transcription in the nucleus. Nat Struct Mol Biol. 2015;22(3):256-64.

152. Guarnerio J, Zhang Y, Cheloni G, Panella R, Mae Katon J, Simpson M, Matsumoto A, Papa A, Loretelli C, Petri A et al. Intragenic antagonistic roles of protein and circRNA in tumorigenesis. Cell Res. 2019; 29(8):628-640.

153. Liu Y, Su H, Zhang J, Liu Y, Feng C, Han F. Back-spliced RNA from retrotransposon binds to centromere and regulates centromeric chromatin loops in maize. PLoS Biol. 2020;18(1):e3000582.

154. Long $Y$, Wang $X$, Youmans DT, Cech TR. How do IncRNAs regulate transcription? Sci Adv. 2017;3(9):eaao2110.

155. Place RF, Li LC, Pookot D, Noonan EJ, Dahiya R. MicroRNA-373 induces expression of genes with complementary promoter sequences. Proc Natl Acad Sci USA. 2008;105(5):1608-13.

156. Wang Y, Lu JH, Wu QN, Jin Y, Wang DS, Chen YX, Liu J, Luo XJ, Meng Q, Pu HY, et al. LncRNA LINRIS stabilizes IGF2BP2 and promotes the aerobic glycolysis in colorectal cancer. Mol Cancer. 2019;18(1):174.

157. Zhang M, Weng W, Zhang Q, Wu Y, Ni S, Tan C, Xu M, Sun H, Liu C, Wei $P$, et al. The IncRNA NEAT1 activates Wnt/ $\beta$-catenin signaling and promotes colorectal cancer progression via interacting with DDX5. J Hematol Oncol. 2018;11(1):113.

158. Lou J, Hao Y, Lin K, Lyu Y, Chen M, Wang H, Zou D, Jiang X, Wang R, Jin D, et al. Circular RNA CDR1as disrupts the p53/MDM2 complex to inhibit Gliomagenesis. Mol Cancer. 2020;19(1):138.

159. Peng L, Li EM, Xu LY. From start to end: phase separation and transcriptional regulation. Biochim Biophys Acta Gene Regul Mech. 2020;1863(12):194641.

160. Agbleke AA, Amitai A, Buenrostro JD, Chakrabarti A, Chu L, Hansen AS, Koenig KM, Labade AS, Liu S, Nozaki T, et al. Advances in chromatin and chromosome research: perspectives from multiple fields. Mol Cell. 2020;79(6):881-901.

161. Erdel F, Rippe K. Formation of chromatin subcompartments by phase separation. Biophys J. 2018;114(10):2262-70.

162. Larson AG, Narlikar GJ. The role of phase separation in heterochromatin formation, function, and regulation. Biochemistry. 2018;57(17):2540-8.

163. Strom AR, Emelyanov AV, Mir M, Fyodorov DV, Darzacq X, Karpen GH. Phase separation drives heterochromatin domain formation. Nature. 2017;547(7662):241-5.

164. Daneshvar K, Ardehali MB, Klein IA, Hsieh FK, Kratkiewicz AJ, Mahpour A, Cancelliere SOL, Zhou C, Cook BM, Li W, et al. IncRNA DIGIT and BRD3 protein form phase-separated condensates to regulate endoderm differentiation. Nat Cell Biol. 2020;22(10):1211-22.

165. McHugh CA, Chen CK, Chow A, Surka CF, Tran C, McDonel P, PandyaJones A, Blanco M, Burghard C, Moradian A, et al. The Xist IncRNA interacts directly with SHARP to silence transcription through HDAC3. Nature. 2015;521(7551):232-6.

166. Neumann P, Jaé N, Knau A, Glaser SF, Fouani Y, Rossbach O, Krüger M, John D, Bindereif A, Grote P, et al. The IncRNA GATA6-AS epigenetically regulates endothelial gene expression via interaction with LOXL2. Nat Commun. 2018;9(1):237.

167. Zhang E, Han L, Yin D, He X, Hong L, Si X, Qiu M, Xu T, De W, Xu L, et al. H3K27 acetylation activated-long non-coding RNA CCAT1 affects cell proliferation and migration by regulating SPRY4 and HOXB13 
expression in esophageal squamous cell carcinoma. Nucleic Acids Res. 2017:45(6):3086-101.

168. Chen RX, Chen X, Xia LP, Zhang JX, Pan ZZ, Ma XD, Han K, Chen JW, Judde JG, Deas O, et al. N(6)-methyladenosine modification of circNSUN2 facilitates cytoplasmic export and stabilizes HMGA2 to promote colorectal liver metastasis. Nat Commun. 2019;10(1):4695.

169. Wu H, HeY, Chen H, Liu Y, Wei B, Chen G, Lin H, Lin H. LncRNA THOR increases osteosarcoma cell stemness and migration by enhancing SOX9 mRNA stability. FEBS Open Bio. 2019;9(4):781-90.

170. Zhang XO, Dong R, Zhang Y, Zhang JL, Luo Z, Zhang J, Chen LL, Yang L. Diverse alternative back-splicing and alternative splicing landscape of circular RNAs. Genome Res. 2016;26(9):1277-87.

171. Romero-Barrios N, Legascue MF, Benhamed M, Ariel F, Crespi M. Splicing regulation by long noncoding RNAs. Nucleic Acids Res. 2018;46(5):2169-84

172. Hutchinson JN, Ensminger AW, Clemson CM, Lynch CR, Lawrence $J B$, Chess A. A screen for nuclear transcripts identifies two linked noncoding RNAs associated with SC35 splicing domains. BMC Genom. 2007;8:39.

173. Cooper DR, Carter G, Li P, Patel R, Watson JE, Patel NA. Long non-coding RNA NEAT1 associates with SRp40 to temporally regulate PPARY2 splicing during adipogenesis in 3T3-L1 cells. Genes. 2014;5(4):1050-63.

174. Sun TT, He J, Liang Q, Ren LL, Yan TT, Yu TC, Tang JY, Bao YJ, Hu Y, Lin Y, et al. LncRNA GCInc1 promotes gastric carcinogenesis and may act as a modular scaffold of WDR5 and KAT2A complexes to specify the histone modification pattern. Cancer Discov. 2016;6(7):784-801

175. Jie M, Wu Y, Gao M, Li X, Liu C, Ouyang Q, Tang Q, Shan C, Lv Y, Zhang K, et al. CircMRPS35 suppresses gastric cancer progression via recruiting KAT7 to govern histone modification. Mol Cancer. 2020;19(1):56.

176. Huang JZ, Chen M, Chen D, Gao XC, Zhu S, Huang H, Hu M, Zhu H, Yan GR. A peptide encoded by a putative IncRNA HOXB-AS3 suppresses colon cancer growth. Mol Cell. 2017;68(1):171-184.e176.

177. Zhang M, Zhao K, Xu X, Yang Y, Yan S, Wei P, Liu H, XU J, Xiao F, Zhou $\mathrm{H}$, et al. A peptide encoded by circular form of LINC-PINT suppresses oncogenic transcriptional elongation in glioblastoma. Nat Commun. 2018:9(1):4475.

178. Pan J, Meng X, Jiang N, Jin X, Zhou C, Xu D, Gong Z. Insights into the noncoding RNA-encoded peptides. Protein Pept Lett. 2018;25(8):720-7.

179. Politz JC, Hogan EM, Pederson T. MicroRNAs with a nucleolar location. RNA (New York, NY). 2009;15(9):1705-15

180. Li ZF, Liang YM, Lau PN, Shen W, Wang DK, Cheung WT, Xue CJ, Poon LM, Lam YW. Dynamic localisation of mature microRNAs in Human nucleoli is influenced by exogenous genetic materials. PLoS One. 2013;8(8):70869.

181. Bai B, Liu H, Laiho M. Small RNA expression and deep sequencing analyses of the nucleolus reveal the presence of nucleolus-associated microRNAs. FEBS Open Bio. 2014:4:441-9.

182. Politz JC, Zhang F, Pederson T. MicroRNA-206 colocalizes with ribosome-rich regions in both the nucleolus and cytoplasm of rat myogenic cells. Proc Natl Acad Sci USA. 2006;103(50):18957-62.

183. Vander Heiden MG, DeBerardinis RJ. Understanding the intersections between metabolism and cancer biology. Cell. 2017;168(4):657-69.

184. Yin J, Ren W, Huang X, Deng J, Li T, Yin Y. Potential mechanisms connecting purine metabolism and cancer therapy. Front Immunol. 2018:9:1697.

185. Fan C, Tang Y, Wang J, Xiong F, Guo C, Wang Y, Zhang S, Gong Z, Wei F, Yang $\mathrm{L}$, et al. Role of long non-coding RNAs in glucose metabolism in cancer. Mol Cancer. 2017;16(1):130

186. Aryal B, Singh AK, Rotllan N, Price N, Fernández-Hernando C. MicroRNAs and lipid metabolism. Curr Opin Lipidol. 2017;28(3):273-80.

187. Ortiz-Pedraza Y, Muñoz-Bello JO, Olmedo-Nieva L, Contreras-Paredes A, Martínez-Ramírez I, Langley E, Lizano M. Non-coding RNAs as key regulators of Glutaminolysis in cancer. Int J Mol Sci. 2020;21 (8):2872.

188. Shabgah AG, Salmaninejad A, Thangavelu L, Alexander M, Yumashev AV, Goleij P, Hedayati-Moghadam M, Mohammadi H, Ahmadi M, Navashenaq JG. The role of non-coding genome in the behavior of infiltrated myeloid-derived suppressor cells in tumor microenvironment; a perspective and state-of-the-art in cancer targeted therapy. Prog Biophys Mol Biol. 2020;161:17-26.

189. Huang D, Chen J, Yang L, Ouyang Q, Li J, Lao L, Zhao J, Liu J, Lu Y, Xing Y, et al. NKILA IncRNA promotes tumor immune evasion by sensitizing T cells to activation-induced cell death. Nat Immunol. 2018;19(10):1112-25.

190. Ji J, Yin Y, Ju H, Xu X, Liu W, Fu Q, Hu J, Zhang X, Sun B. Long non-coding RNA Lnc-Tim3 exacerbates CD8 T cell exhaustion via binding to Tim-3 and inducing nuclear translocation of Bat3 in HCC. Cell Death Dis. 2018;9(5):478

191. Shang A, Wang W, Gu C, Chen C, Zeng B, Yang Y, Ji P, Sun J, Wu J, Lu $W$, et al. Long non-coding RNA HOTTIP enhances IL-6 expression to potentiate immune escape of ovarian cancer cells by upregulating the expression of PD-L1 in neutrophils. J Exp Clin Cancer Res CR. 2019;38(1):411.

192. Vignard V, Labbé M, Marec N, André-Grégoire G, Jouand N, Fonteneau JF, Labarrière N, Fradin D. MicroRNAs in tumor exosomes drive immune escape in Melanoma. Cancer Immunol Res. 2020;8(2):255-67.

193. Ye SB, Zhang H, Cai TT, Liu YN, Ni JJ, He J, Peng JY, Chen QY, Mo HY, Jun $C$, et al. Exosomal miR-24-3p impedes T-cell function by targeting FGF11 and serves as a potential prognostic biomarker for nasopharyngeal carcinoma. J Pathol. 2016;240(3):329-40.

194. Zhang M, Gao D, Shi Y, Wang Y, Joshi R, Yu Q, Liu D, Alotaibi F, Zhang Y, Wang $H$, et al. miR-149-3p reverses CD8(+) T-cell exhaustion by reducing inhibitory receptors and promoting cytokine secretion in breast cancer cells. Open Biology. 2019;9(10):190061.

195. Chen J, Yu Y, Li H, Hu Q, Chen X, He Y, Xue C, Ren F, Ren Z, Li J, et al. Long non-coding RNA PVT1 promotes tumor progression by regulating the miR-143/HK2 axis in gallbladder cancer. Mol Cancer. 2019;18(1):33.

196. Fong MY, Zhou W, Liu L, Alontaga AY, Chandra M, Ashby J, Chow A, O'Connor ST, Li S, Chin AR, et al. Breast-cancer-secreted miR-122 reprograms glucose metabolism in premetastatic niche to promote metastasis. Nat Cell Biol. 2015;17(2):183-94.

197. Li H, Yang F, Hu A, Wang X, Fang E, Chen Y, Li D, Song H, Wang J, Guo Y, et al. Therapeutic targeting of circ-CUX1/EWSR1/MAZ axis inhibits glycolysis and neuroblastoma progression. EMBO Mol Med. 2019:11(12):10835.

198. Li Q, Pan X, Zhu D, Deng Z, Jiang R, Wang X. Circular RNA MAT2B promotes glycolysis and malignancy of hepatocellular carcinoma through the miR-338-3p/PKM2 axis under hypoxic stress. Hepatology. 2019;70(4):1298-316.

199. Ma F, Liu X, Zhou S, Li W, Liu C, Chadwick M, Qian C. Long non-coding RNA FGF13-AS1 inhibits glycolysis and stemness properties of breast cancer cells through FGF13-AS1/IGF2BPs/Myc feedback loop. Cancer Lett. 2019;450:63-75.

200. Ren S, Liu J, Feng Y, Li Z, He L Li L Cao X, Wang Z, Zhang Y. Knockdown of circDENND4C inhibits glycolysis, migration and invasion by up-regulating miR-200b/c in breast cancer under hypoxia. J Exp Clin Cancer Res: CR. 2019;38(1):388.

201. Wang F, Liang R, Tandon N, Matthews ER, Shrestha S, Yang J, Soibam B, Yang J, Liu Y. H19X-encoded miR-424(322)/-503 cluster: emerging roles in cell differentiation, proliferation, plasticity and metabolism. Cell Mol Life Sci. 2019:76(5):903-20.

202. Liao M, Liao W, Xu N, Li B, Liu F, Zhang S, Wang Y, Wang S, Zhu Y, Chen $D$, et al. LncRNA EPB41L4A-AS1 regulates glycolysis and glutaminolysis by mediating nucleolar translocation of HDAC2. EBioMedicine. 2019:41:200-13.

203. Tang J, Yan T, Bao Y, Shen C, Yu C, Zhu X, Tian X, Guo F, Liang Q, Liu Q, et al. LnCRNA GLCC1 promotes colorectal carcinogenesis and glucose metabolism by stabilizing c-Myc. Nat Commun. 2019;10(1):3499.

204. Wang C, Li Y, Yan S, Wang H, Shao X, Xiao M, Yang B, Qin G, Kong R, Chen $R$, et al. Interactome analysis reveals that IncRNA HULC promotes aerobic glycolysis through LDHA and PKM2. Nat Commun. 2020;11(1):3162.

205. Zhu W, Zhou BL, Rong LJ, Ye L, Xu HJ, Zhou Y, Yan XJ, Liu WD, Zhu B, Wang $L$, et al. Roles of PTBP1 in alternative splicing, glycolysis, and oncogensis. J Zhejiang Univ Sci B. 2020;21(2):122-36.

206. Chen F, Chen J, Yang L, Liu J, Zhang X, Zhang Y, Tu Q, Yin D, Lin D, Wong PP, et al. Extracellular vesicle-packaged HIF-1a-stabilizing IncRNA from tumour-associated macrophages regulates aerobic glycolysis of breast cancer cells. Nat Cell Biol. 2019;21(4):498-510.

207. Zhao E, Maj T, Kryczek I, Li W, Wu K, Zhao L, Wei S, Crespo J, Wan S, Vatan $L$, et al. Cancer mediates effector $T$ cell dysfunction by targeting microRNAs and EZH2 via glycolysis restriction. Nat Immunol. 2016:17(1):95-103. 
208. Zhao L, Ji G, Le X, Wang C, Xu L, Feng M, Zhang Y, Yang H, Xuan Y, Yang $Y$, et al. Long noncoding RNA LINC00092 acts in cancer-associated fibroblasts to drive glycolysis and progression of ovarian cancer. Cancer Res. 2017;77(6):1369-82.

209. Malakar P, Stein I, Saragovi A, Winkler R, Stern-Ginossar N, Berger M, Pikarsky E, Karni R. Long noncoding RNA MALAT1 regulates cancer glucose metabolism by enhancing mTOR-mediated translation of TCF7L2. Cancer Res. 2019;79(10):2480-93.

210. Nanni S, Aiello A, Salis C, Re A, Cencioni C, Bacci L, Pierconti F, Pinto F, Ripoli C, Ostano P, et al. Metabolic reprogramming by malat1 depletion in prostate cancer. Cancers Basel. 2020;13(1):15.

211. Hou ZH, Xu XW, Fu XY, Zhou LD, Liu SP, Tan DM. Long non-coding RNA MALAT1 promotes angiogenesis and immunosuppressive properties of HCC cells by sponging miR-140. Am J Physiol Cell Physiol. 2020;318(3):C649-c663.

212. Zhou Q, Tang X, Tian X, Tian J, Zhang Y, Ma J, Xu H, Wang S. LncRNA MALAT1 negatively regulates MDSCs in patients with lung cancer. J Cancer. 2018;9(14):2436-42.

213. Zheng T, Ma G, Tang M, Li Z, Xu R. IL-8 Secreted from M2 Macrophages Promoted Prostate Tumorigenesis via STAT3/MALAT1 Pathway. Int J Mol Sci. 2018;20(1):98

214. Dai Q, Li N, Zhou X. Increased miR-21a provides metabolic advantages through suppression of FBP1 expression in non-small cell lung cancer cells. Am J Cancer Res. 2017;7(11):2121-30.

215. Zhang Z, Huang $X$, Wang $E$, Huang $Y$, Yang R. Suppression of Mll1complex by Stat3/Cebpß-induced miR-21a/21b/181b maintains the accumulation, homeostasis, and immunosuppressive function of polymorphonuclear myeloid-derived suppressor cells. J Immunol. 2020:204(12):3400-15.

216. Zhang X, Li F, Tang Y, Ren Q, Xiao B, Wan Y, Jiang S. miR-21 a in exosomes from Lewis lung carcinoma cells accelerates tumor growth through targeting PDCD4 to enhance expansion of myeloid-derived suppressor cells. Oncogene. 2020;39(40):6354-69.

217. Li N, Qin JF, Han X, Jin FJ, Zhang JH, Lan L, Wang Y. miR-21 a negatively modulates tumor suppressor genes PTEN and miR-200c and further promotes the transformation of M2 macrophages. Immunol Cell Biol. 2018;96(1):68-80.

218. Zhao S, Zhang X, Shi Y, Cheng L, Song T, Wu B, Li J, Yang H. MIEF2 over-expression promotes tumor growth and metastasis through reprogramming of glucose metabolism in ovarian cancer. J Exp Clin Cancer Res: CR. 2020;39(1):286

219. Ma LL, Liang L, Zhou D, Wang SW. Tumor suppressor miR-424-5p abrogates ferroptosis in ovarian cancer through targeting ACSL4. Neoplasma. 2021;68(1):165-73.

220. Bevers EM, Williamson PL. Phospholipid scramblase: an update. FEBS Lett. 2010;584(13):2724-30.

221. Dastmalchi N, Hosseinpourfeizi MA, Khojasteh SMB, Baradaran B, Safaralizadeh $\mathrm{R}$. Tumor suppressive activity of miR-424-5p in breast cancer cells through targeting PD-L1 and modulating PTEN/PI3K/AKT/mTOR signaling pathway. Life Sci. 2020;259:118239.

222. Tang R, Hua J, Xu J, Liang C, Meng Q, Liu J, Zhang B, Yu X, Shi S. The role of ferroptosis regulators in the prognosis, immune activity and gemcitabine resistance of pancreatic cancer. Ann Transl Med. 2020:8(21):1347.

223. Tang R, Xu J, Zhang B, Liu J, Liang C, Hua J, Meng Q, Yu X, Shi S. Ferroptosis, necroptosis, and pyroptosis in anticancer immunity. J Hematol Oncol. 2020;13(1):110.

224. Elhanati S, Ben-Hamo R, Kanfi Y, Varvak A, Glazz R, Lerrer B, Efroni S, Cohen HY. Reciprocal regulation between SIRT6 and miR-122 controls liver metabolism and predicts hepatocarcinoma prognosis. Cell Rep. 2016:14(2):234-42.

225. Rady M, Watzl C, Claus M, Khorshid O, Mahran L, Abou-Aisha K. Altered expression of miR-181a and miR-146a does not change the expression of surface NCRs in human NK cells. Sci Rep. 2017;7:41381.

226. Liu X, Luo M, Meng H, Zeng Q, Xu L, Hu B, Luo Y, Liu C, Luo Z, Yang H: MiR-181a regulates $C D 4(+) T$ cell activation and differentiation by targeting IL-2 in the pathogenesis of myasthenia gravis. Eur J Immunol. 2019

227. Ye Z, Li G, Kim C, Hu B, Jadhav RR, Weyand CM, Goronzy JJ. Regulation of miR-181a expression in T cell aging. Nat Commun. 2018;9(1):3060

228. Knarr M, Avelar RA, Sekhar SC, Kwiatkowski LJ, Dziubinski ML, McAnulty J, Skala S, Avril S, Drapkin R, DiFeo A. miR-181a initiates and perpetuates oncogenic transformation through the regulation of innate immune signaling. Nat Commun. 2020;11(1):3231.

229. Ma J, Yang Y, Fu Y, Guo F, Zhang X, Xiao S, Zhu W, Huang Z, Zhang J, Chen J. PIAS3-mediated feedback loops promote chronic colitis-associated malignant transformation. Theranostics. 2018;8(11):3022-37.

230. Chu B, Wu T, Miao L, Mei Y, Wu M. MiR-181a regulates lipid metabolism via IDH1. Sci Rep. 2015:5:8801.

231. Li X, Deng S, Pang X, Song Y, Luo S, Jin L, Pan Y. LncRNA NEAT1 silenced miR-133b promotes migration and invasion of breast cancer cells. Int J Mol Sci. 2019;20(15):3616.

232. Müller V, Oliveira-Ferrer L, Steinbach B, Pantel K, Schwarzenbach H. Interplay of IncRNA H19/miR-675 and IncRNA NEAT1/miR-204 in breast cancer. Mol Oncol. 2019;13(5):1137-49.

233. Wang W, Ge L, Xu XJ, Yang T, Yuan Y, Ma XL, Zhang XH. LncRNA NEAT1 promotes endometrial cancer cell proliferation, migration and invasion by regulating the miR-144-3p/EZH2 axis. Radiol Oncol. 2019;53(4):434-42.

234. Yu X, Li Z, Zheng H, Chan MT, Wu WK. NEAT1: A novel cancer-related long non-coding RNA. Cell Prolif. 2017;50(2):12329.

235. Liu X, Liang Y, Song R, Yang G, Han J, Lan Y, Pan S, Zhu M, Liu Y, Wang $Y$, et al. Long non-coding RNA NEAT1-modulated abnormal lipolysis via ATGL drives hepatocellular carcinoma proliferation. Mol Cancer. 2018;17(1):90

236. Ma F, Lei YY, Ding MG, Luo LH, Xie YC, Liu XL. LncRNA NEAT1 interacted with DNMT1 to regulate malignant phenotype of cancer cell and cytotoxic T cell infiltration via epigenetic inhibition of p53, cGAS, and STING in lung cancer. Front Genet. 2020;11:250.

237. Zhang P, Cao L, Zhou R, Yang X, Wu M. The IncRNA Neat1 promotes activation of inflammasomes in macrophages. Nat Commun. 2019;10(1):1495

238. Zhang M, Zheng Y, Sun Y, Li S, Chen L, Jin X, Hou X, Liu X, Chen Q, Li J, et al. Knockdown of NEAT1 induces tolerogenic phenotype in dendritic cells by inhibiting activation of NLRP3 inflammasome. Theranostics. 2019;9(12):3425-42

239. Gao Y, Fang P, Li WJ, Zhang J, Wang GP, Jiang DF, Chen FP. LncRNA NEAT1 sponges miR-214 to regulate M2 macrophage polarization by regulation of $\mathrm{B} 7-\mathrm{H} 3$ in multiple myeloma. Mol Immunol. 2020;117:20-8

240. Labadie BW, Bao R, Luke JJ. Reimagining IDO pathway inhibition in cancer immunotherapy via downstream focus on the tryptophankynurenine-aryl hydrocarbon axis. Clin Cancer Res. 2019;25(5):1462-71.

241. Platten M, Nollen EAA, Röhrig UF, Fallarino F, Opitz CA. Tryptophan metabolism as a common therapeutic target in cancer, neurodegeneration and beyond. Nat Rev Drug Discov. 2019;18(5):379-401.

242. Platten M, Wick W, Van den Eynde BJ. Tryptophan catabolism in cancer: beyond IDO and tryptophan depletion. Cancer Res. 2012;72(21):5435-40

243. Liu M, Wang X, Wang L, Ma X, Gong Z, Zhang S, Li Y. Targeting the IDO1 pathway in cancer: from bench to bedside. J Hematol Oncol. 2018;11(1):100

244. Altman BJ, Stine ZE, Dang CV. From Krebs to clinic: glutamine metabolism to cancer therapy. Nat Rev Cancer. 2016;16(10):619-34.

245. Li T, Le A. Glutamine Metabolism in Cancer. Adv Exp Med Biol. 2018;1063:13-32.

246. Fujisaka Y, Iwata T, Tamai K, Nakamura M, Mochizuki M, Shibuya R, Yamaguchi K, Shimosegawa T, Satoh K. Long non-coding RNA HOTAIR upregulates chemokine ( $\mathrm{C}-\mathrm{C}$ motif) ligand 2 and promotes proliferation of macrophages and myeloid-derived suppressor cells in hepatocellular carcinoma cell lines. Oncol Lett. 2018;15(1):509-14.

247. Liu L, Cui S, Wan T, Li X, Tian W, Zhang R, Luo L, Shi Y. Long noncoding RNA HOTAIR acts as a competing endogenous RNA to promote glioma progression by sponging miR-126-5p. J Cell Physiol. 2018;233(9):6822-31.

248. O'Connell RM, Rao DS, Chaudhuri AA, Boldin MP, Taganov KD, Nicoll J, Paquette RL, Baltimore D. Sustained expression of microRNA-155 in hematopoietic stem cells causes a myeloproliferative disorder. J Exp Med. 2008;205(3):585-94

249. Pauley KM, Stewart CM, Gauna AE, Dupre LC, Kuklani R, Chan AL, Pauley BA, Reeves WH, Chan EK, Cha S. Altered miR-146a expression in Sjögren's syndrome and its functional role in innate immunity. Eur $」$ Immunol. 2011:41(7):2029-39. 
250. Sahraei M, Chaube B, Liu Y, Sun J, Kaplan A, Price NL, Ding W, Oyaghire S, García-Milian R, Mehta S, et al. Suppressing miR-21 activity in tumor-associated macrophages promotes an antitumor immune response. J Clin Invest. 2019;129(12):5518-36.

251. Zhihua Y, Yulin T, Yibo W, Wei D, Yin C, Jiahao X, Runqiu J, Xuezhong $X$. Hypoxia decreases macrophage glycolysis and $M 1$ percentage by targeting microRNA-30c and mTOR in human gastric cancer. Cancer Sci. 2019;110(8):2368-77.

252. Zhang T, Zhang Z, Li F, Ping Y, Qin G, Zhang C, Zhang Y. miR-143 Regulates Memory T Cell Differentiation by Reprogramming T Cell Metabolism. J Immunol. 2018;201(7):2165-75.

253. Ouimet M, Ediriweera HN, Gundra UM, Sheedy FJ, Ramkhelawon B, Hutchison SB, Rinehold K, van Solingen C, Fullerton MD, Cecchini K, et al. MicroRNA-33-dependent regulation of macrophage metabolism directs immune cell polarization in atherosclerosis. J Clin Invest. 2015;125(12):4334-48.

254. Lin JB, Moolani HV, Sene A, Sidhu R, Kell P, Lin JB, Dong Z, Ban N, Ory DS, Apte RS: Macrophage microRNA-150 promotes pathological angiogenesis as seen in age-related macular degeneration. JCI Insight 2018; 3(7).

255. Sheng Y, Jiang Q, Dong X, Liu J, Liu L, Wang H, Wang L, Li H, Yang $X$, Dong J. 3-Bromopyruvate inhibits the malignant phenotype of malignantly transformed macrophages and dendritic cells induced by glioma stem cells in the glioma microenvironment via miR-449a/ MCT1. Biomed Pharmacother. 2020;121:109610.

256. Elia I, Haigis MC. Metabolites and the tumour microenvironment: from cellular mechanisms to systemic metabolism. Nat Metab. 2021;3(1):21-32.

257. Garcia-Bermudez J, Baudrier L, La K, Zhu XG, Fidelin J, Sviderskiy VO, Papagiannakopoulos T, Molina H, Snuderl M, Lewis CA, et al. Aspartate is a limiting metabolite for cancer cell proliferation under hypoxia and in tumours. Nat Cell Biol. 2018;20(7):775-81.

258. Sullivan LB, Gui DY, Vander Heiden MG. Altered metabolite levels in cancer: implications for tumour biology and cancer therapy. Nat Rev Cancer. 2016;16(11):680-93.

259. Geiger R, Rieckmann JC, Wolf T, Basso C, Feng Y, Fuhrer T, Kogadeeva M, Picotti P, Meissner F, Mann M, et al. L-arginine modulates T cell metabolism and enhances survival and anti-tumor activity. Cell. 2016;167(3):829-842.e813.

260. Raber P, Ochoa AC, Rodríguez PC. Metabolism of L-arginine by myeloid-derived suppressor cells in cancer: mechanisms of $T$ cell suppression and therapeutic perspectives. Immunol Invest. 2012;41(6-7):614-34

261. Tu MJ, Pan YZ, Qiu JX, Kim EJ, Yu AM. MicroRNA-1291 targets the FOXA2-AGR2 pathway to suppress pancreatic cancer cell proliferation and tumorigenesis. Oncotarget. 2016;7(29):45547-61.

262. Tu MJ, Duan Z, Liu Z, Zhang C, Bold RJ, Gonzalez FJ, Kim EJ, Yu AM. MicroRNA-1291-5p sensitizes pancreatic carcinoma cells to arginine deprivation and chemotherapy through the regulation of arginolysis and glycolysis. Mol Pharmacol. 2020;98(6):686-94

263. El-Lithy GM, El-Bakly WM, Matboli M, Abd-Alkhalek HA, Masoud SI, Hamza M. Prophylactic L-arginine and ibuprofen delay the development of tactile allodynia and suppress spinal miR-155 in a rat model of diabetic neuropathy. Transl Res. 2016;177:85-97.e81.

264. Li L, Han W, Chen Y, Chen Y. MiR-3613-3p inhibits hypertrophic scar formation by down-regulating arginine and glutamate-rich 1. Mol Cell Biochem. 2021;476(2):1025-36.

265. Zhang H, Wang L, Peng F, Wang X, Gong H. L-arginine ameliorates highfat diet-induced atherosclerosis by downregulating miR-221. Biomed Res Int. 2020;2020:4291327.

266. Zhou G, Xu Q, Wu F, Wang M, Chen L, Hu L, Zhao J, Loor JJ, Zhang J. Arginine alters miRNA expression involved in development and proliferation of rat mammary tissue. Animals. 2021;11(2):535.

267. Beyersdorf N, Müller N. Sphingomyelin breakdown in T cells: role in activation, effector functions and immunoregulation. Biol Chem. 2015;396(6-7):749-58.

268. Chan G, Ochi A. Sphingomyelin-ceramide turnover in CD28 costimulatory signaling. Eur J Immunol. 1995;25(7):1999-2004.

269. Kukreti H, Amuthavalli K. MicroRNA-34a causes ceramide accumulation and effects insulin signaling pathway by targeting ceramide kinase (CERK) in aging skeletal muscle. J Cell Biochem. 2020;121(5-6):3070-89.
270. Liu L, Ye Q, Liu L, Bihl JC, Chen Y, Liu J, Cheng Q. C6-ceramide treatment inhibits the proangiogenic activity of multiple myeloma exosomes via the miR-29b/Akt pathway. J Transl Med. 2020;18(1):298.

271. Qiu J, Villa M, Sanin DE, Buck MD, O'Sullivan D, Ching R, Matsushita M, Grzes KM, Winkler F, Chang CH, et al. Acetate promotes T cell effector function during glucose restriction. Cell Rep. 2019;27(7):2063-2074. e2065.

272. Li S, Weng J, Song F, Li L, Xiao C, Yang W, Xu J. Circular RNA circZNF566 promotes hepatocellular carcinoma progression by sponging miR-4738-3p and regulating TDO2 expression. Cell Death Dis, 2020;11(6):452.

273. Li C, Wang X, Yuan F, Zhao Z, Zhang B, Zhang J, Li W, Liu T. MiR-669b-3p regulates $\mathrm{CD} 4(+) T$ cell function by down-regulating indoleamine-2, 3-dioxygenase. Transpl Immunol. 2020;62:101320.

274. Chang CH, Curtis JD, Maggi LB Jr, Faubert B, Villarino AV, O'Sullivan D, Huang SC, van der Windt GJ, Blagih J, Qiu J, et al. Posttranscriptional control of $\mathrm{T}$ cell effector function by aerobic glycolysis. Cell. 2013;153(6):1239-51.

275. Fanet H, Capuron L, Castanon N, Calon F, Vancassel S. Tetrahydrobioterin (BH4) pathway: from metabolism to neuropsychiatry. Curr Neuropharmacol. 2020;19:591-609.

276. Cronin SJF, Seehus C, Weidinger A, Talbot S, Reissig S, Seifert M, Pierson Y, McNeill E, Longhi MS, Turnes BL, et al. The metabolite BH4 controls $\mathrm{T}$ cell proliferation in autoimmunity and cancer. Nature. 2018;563(7732):564-8.

277. Yuan S, Wang YX, Gong PH, Meng CY. MiR-124 inhibits spinal neuronal apoptosis through binding to GCH1. Eur Rev Med Pharmacol Sci. 2019;23(11):4564-74.

278. Wei J, Zhang Y, Li Z, Wang X, Chen L, Du J, Liu J, Liu J, Hou Y. GCH1 attenuates cardiac autonomic nervous remodeling in canines with atrial-tachypacing via tetrahydrobiopterin pathway regulated by microRNA-206. Pacing Clin Electrophysiol PACE. 2018;41(5):459-71.

279. Meeker S, Seamons A, Maggio-Price L, Paik J. Protective links between vitamin D, inflammatory bowel disease and colon cancer. World J Gastroenterol. 2016;22(3):933-48.

280. Ibrahim HM, Abdel Ghaffar FR, El-Elaimy IA, Gouida MS. Abd El Latif HM: antitumor and immune-modulatory efficacy of dual-treatment based on levamisole and/or taurine in Ehrlich ascites carcinoma-bearing mice. Biomed Pharmacother. 2018;106:43-9.

281. Yan Z, Banerjee R. Redox remodeling as an immunoregulatory strategy. Biochemistry. 2010;49(6):1059-66.

282. Ghaforui-Fard S, Vafaee R, Taheri M. Taurine-upregulated gene 1 : a functional long noncoding RNA in tumorigenesis. J Cell Physiol. 2019;234(10):17100-12.

283. Wang Z, Chen X, Liu N, Shi Y, Liu Y, Ouyang L, Tam S, Xiao D, Liu S, Wen F, et al. A nuclear long non-coding RNA LINC00618 accelerates ferroptosis in a manner dependent upon apoptosis. Mol Therapy. 2021:29(1):263-74.

284. Wu Y, Sun X, Song B, Qiu X, Zhao J. MiR-375/SLC7A11 axis regulates oral squamous cell carcinoma proliferation and invasion. Cancer Med. 2017:6(7):1686-97.

285. Zhu JH, De Mello RA, Yan QL, Wang JW, Chen Y, Ye QH, Wang ZJ, Tang HJ, Huang T. MiR-139-5p/SLC7A11 inhibits the proliferation, invasion and metastasis of pancreatic carcinoma via PI3K/Akt signaling pathway. Biochim Biophys Acta Mol Basis Dis. 2020;1866(6):165747.

286. Wang L, Zhou S, Guo B. Vitamin D suppresses ovarian cancer growth and invasion by targeting long non-coding RNA CCAT2. Int J Mol Sci. 2020;21(7):2334.

287. Zuo S, Wu L, Wang Y, Yuan X. Long non-coding RNA MEG3 activated by vitamin $\mathrm{D}$ suppresses glycolysis in colorectal cancer via promoting c-Myc degradation. Front Oncol. 2020;10:274.

288. Arboleda JF, Fernandez GJ, Urcuqui-Inchima S. Vitamin D-mediated attenuation of miR-155 in human macrophages infected with dengue virus: Implications for the cytokine response. Infection Genet Evol. 2019;69:12-21.

289. Huang B, Song BL, Xu C. Cholesterol metabolism in cancer: mechanisms and therapeutic opportunities. Nat Metab. 2020;2(2):132-41.

290. Ma X, Xiao L, Liu L, Ye L, Su P, Bi E, Wang Q, Yang M, Qian J, Yi Q. Cell Metab. 2021:33:1001.

291. Eibinger G, Fauler G, Bernhart E, Frank S, Hammer A, Wintersperger A, Eder $\mathrm{H}$, Heinemann A, Mischel PS, Malle E, et al. On the role 
of 25-hydroxycholesterol synthesis by glioblastoma cell lines. Implications for chemotactic monocyte recruitment. Exp Cell Res. 2013;319(12):1828-38.

292. Baek AE, Yu YA, He S, Wardell SE, Chang CY, Kwon S, Pillai RV, McDowell $\mathrm{HB}$, Thompson JW, Dubois LG, et al. The cholesterol metabolite 27 hydroxycholesterol facilitates breast cancer metastasis through its actions on immune cells. Nat Commun. 2017:8(1):864.

293. Sallam T, Jones M, Thomas BJ, Wu X, Gilliland T, Qian K, Eskin A, Casero $D$, Zhang Z, Sandhu J, et al. Transcriptional regulation of macrophage cholesterol efflux and atherogenesis by a long noncoding RNA. Nat Med. 2018;24(3):304-12.

294. Wagschal A, Najafi-Shoushtari SH, Wang L, Goedeke L, Sinha S, deLemos AS, Black JC, Ramírez CM, Li Y, Tewhey R, et al. Genome-wide identification of microRNAs regulating cholesterol and triglyceride homeostasis. Nat Med. 2015;21(11):1290-7.

295. Zhu T, Corraze G, Plagnes-Juan E, Skiba-Cassy S. Cholesterol metabolism regulation mediated by SREBP-2, LXRa and miR-33a in rainbow trout (Oncorhynchus mykiss) both in vivo and in vitro. PLOS ONE. 2020;15(2):e0223813.

296. Zhang L, LV Y, Xian G, Lin Y. 25-hydroxycholesterol promotes RANKLinduced osteoclastogenesis through coordinating NFATc1 and Sp1 complex in the transcription of miR-139-5p. Biochem Biophys Res Commun. 2017;485(4):736-41.

297. Dias IHK, Brown CL, Shabir K, Polidori MC, Griffiths HR. miRNA 933 expression by endothelial cells is increased by 27 -hydroxycholesterol and is more prevalent in plasma from dementia patients. J Alzheimers Dis. 2018;64(3):1009-17.

298. Cubillos-Ruiz JR, Silberman PC, Rutkowski MR, Chopra S, Perales-Puchalt A, Song M, Zhang S, Bettigole SE, Gupta D, Holcomb K, et al. ER stress sensor XBP1 controls anti-tumor immunity by disrupting dendritic cell homeostasis. Cell. 2015;161(7):1527-38.

299. Herber DL, Cao W, Nefedova Y, Novitskiy SV, Nagaraj S, Tyurin VA, Corzo $\mathrm{A}, \mathrm{Cho} \mathrm{HI}$, Celis E, Lennox B, et al. Lipid accumulation and dendritic cell dysfunction in cancer. Nat Med. 2010;16(8):880-6.

300. Li Q, Wang Y, Wu S, Zhou Z, Ding X, Shi R, Thorne RF, Zhang XD, Hu W, Wu M. CircACC1 regulates assembly and activation of AMPK complex under metabolic stress. Cell Metab. 2019;30(1):157-173.e157.

301. He W, Liang B, Wang C, Li S, Zhao Y, Huang Q, Liu Z, Yao Z, Wu Q, Liao $W$, et al. MSC-regulated InCRNA MACC1-AS1 promotes stemness and chemoresistance through fatty acid oxidation in gastric cancer. Oncogene. 2019;38(23):4637-54.

302. Shang C, Wang W, Liao Y, Chen Y, Liu T, Du Q, Huang J, Liang Y, Liu J, Zhao Y, et al. LNMICC promotes nodal metastasis of cervical cancer by reprogramming fatty acid metabolism. Cancer Res. 2018;78(4):877-90.

303. Hanin G, Yayon N, Tzur Y, Haviv R, Bennett ER, Udi S, Krishnamoorthy YR, Kotsiliti E, Zangen R, Efron B, et al. miRNA-132 induces hepatic steatosis and hyperlipidaemia by synergistic multitarget suppression. Gut. 2018;67(6):1124-34

304. Weiss JM, Davies LC, Karwan M, lleva L, Ozaki MK, Cheng RY, Ridnour LA, Annunziata CM, Wink DA, McVicar DW. Itaconic acid mediates crosstalk between macrophage metabolism and peritoneal tumors. J Clin Invest. 2018;128(9):3794-805.

305. Ganta VC, Choi MH, Kutateladze A, Fox TE, Farber CR, Annex BH. A MicroRNA93-interferon regulatory Factor-9-Immunoresponsive gene1-Itaconic acid pathway modulates M2-Like macrophage polarization to revascularize ischemic muscle. Circulation. 2017;135(24):2403-25.

306. de Sousa CL, Monteiro G. Gemcitabine: metabolism and molecular mechanisms of action, sensitivity and chemoresistance in pancreatic cancer. Eur J Pharmacol. 2014;741:8-16.

307. Halbrook CJ, Pontious C, Kovalenko I, Lapienyte L, Dreyer S, Lee HJ Thurston G, Zhang Y, Lazarus J, Sajjakulnukit P, et al. Macrophagereleased pyrimidines inhibit gemcitabine therapy in pancreatic cancer. Cell Metab. 2019;29(6):1390-1399.e1396.

308. Xu F, Ye ML, Zhang YP, Li WJ, Li MT, Wang HZ, Qiu X, Xu Y, Yin JW, Hu Q et al. MicroRNA-375-3p enhances chemosensitivity to 5 -fluorouracil by targeting thymidylate synthase in colorectal cancer. Cancer Sci. 2020;111(5):1528-41.

309. Fournel L, Wu Z, Stadler N, Damotte D, Lococo F, Boulle G, SégalBendirdjian E, Bobbio A, Icard P, Trédaniel J, et al. Cisplatin increases PD-L1 expression and optimizes immune check-point blockade in non-small cell lung cancer. Cancer Lett. 2019;464:5-14.
310. Ho PL, Williams SB, Kamat AM. Immune therapies in non-muscle invasive bladder cancer. Curr Treat Options Oncol. 2015;16(2):5.

311. Chen H, Chong W, Wu Q, Yao Y, Mao M, Wang X. Association of LRP1B mutation with tumor mutation burden and outcomes in melanoma and non-small cell lung cancer patients treated with immune checkpoint blockades. Front Immunol. 2019;10:1113.

312. Stovgaard ES, Nielsen D, Hogdall E, Balslev E. Triple negative breast cancer: prognostic role of immune-related factors: a systematic review. Acta Oncolog (Stockholm, Sweden). 2018;57(1):74-82.

313. Zheng Z, Sun R, Zhao HJ, Fu D, Zhong HJ, Weng XQ, Qu B, Zhao Y, Wang L, Zhao WL. MiR155 sensitized B-lymphoma cells to anti-PD-L1 antibody via PD-1/PD-L1-mediated lymphoma cell interaction with CD8+T cells. Mol Cancer. 2019;18(1):54

314. Gao L, Guo Q, Li X, Yang X, Ni H, Wang T, Zhao Q, Liu H, Xing Y, Xi T, et al. MiR-873/PD-L1 axis regulates the stemness of breast cancer cells. EBioMedicine. 2019:41:395-407.

315. Wang J, Zhao X, Wang Y, Ren F, Sun D, Yan Y, Kong X, Bu J, Liu M, Xu S. circRNA-002178 act as a ceRNA to promote PDL1/PD1 expression in lung adenocarcinoma. Cell Death Dis. 2020;11(1):32.

316. Huang XY, Zhang PF, Wei CY, Peng R, Lu JC, Gao C, Cai JB, Yang X, Fan J, Ke AW, et al. Circular RNA circMET drives immunosuppression and antiPD1 therapy resistance in hepatocellular carcinoma via the miR-30-5p/ snail/DPP4 axis. Mol Cancer. 2020;19(1):92.

317. He H, Lu M, Shi H, Yue G, Luo H. Vaspin regulated cartilage cholesterol metabolism through miR155/LXRa and participated in the occurrence of osteoarthritis in rats. Life Sci. 2021;269:119096.

318. Zhang Y, Zhang C, Zhao Q, Wei W, Dong Z, Shao L, Li J, Wu W, Zhang $H$, Huang $H$, et al. The miR-873/NDFIP1 axis promotes hepatocellular carcinoma growth and metastasis through the AKT/mTOR-mediated Warburg effect. Am J Cancer Res. 2019;9(5):927-44.

319. Nguyen LH, Zhu H. Lin 28 and let-7 in cell metabolism and cancer. Trans Pediatr. 2015;4(1):4-11.

320. Xia W, Chen H, Chen D, Ye Y, Xie C, Hou M. PD-1 inhibitor inducing exosomal miR-34a-5p expression mediates the cross talk between cardiomyocyte and macrophage in immune checkpoint inhibitor-related cardiac dysfunction. J Immunother Cancer. 2020;8(2):001293.

321. Hua JT, Ahmed M, Guo H, Zhang Y, Chen S, Soares F, Lu J, Zhou S, Wang $\mathrm{M}$, Li H, et al. Risk SNP-mediated promoter-enhancer switching drives prostate cancer through IncRNA PCAT19. Cell. 2018;174(3):564-575. e518.

322. Xie YH, Hu J. Suppression of long non-coding RNA PCAT19 inhibits glioma cell proliferation and invasion, and increases cell apoptosis through regulation of MELK targeted by miR-142-5p. Genes Genom. 2020;42(11):1299-310.

323. Xu S, Guo J, Zhang W. IncRNA PCAT1 9 promotes the proliferation of laryngocarcinoma cells via modulation of the miR-182/PDK4 axis. J Cell Biochem. 2019;120(8):12810-21.

324. Zhang $X$, Wang $Q, X u Y$, Wang $B$, Jia $C$, Wang $L$, Sun $H$, Zhao $H$, Wang Z, Zou $Q$, et al. IncRNA PCAT19 negatively regulates $p 53$ in non-small cell lung cancer. Oncol Lett. 2019;18(6):6795-800.

325. Li N, Zhan X. Identification of clinical trait-related IncRNA and mRNA biomarkers with weighted gene co-expression network analysis as useful tool for personalized medicine in ovarian cancer. EPMA J. 2019;10(3):273-90.

326. Lin X, Jiang T, Bai J, Li J, Wang T, Xiao J, Tian Y, Jin X, Shao T, Xu J, et al. Characterization of transcriptome transition associates long noncoding RNAs with glioma progression. Mol Therapy Nucl Acids. 2018;13:620-32.

327. Gill KS, Fernandes P, O'Donovan TR, McKenna SL, Doddakula KK, Power DG, Soden DM, Forde PF. Glycolysis inhibition as a cancer treatment and its role in an anti-tumour immune response. Biochim Biophys Acta. 2016;1866(1):87-105.

328. Kishton RJ, Sukumar M, Restifo NP. Metabolic regulation of T cell longevity and function in tumor immunotherapy. Cell Metab. 2017:26(1):94-109.

329. Loftus RM, Finlay DK. Immunometabolism: cellular metabolism turns immune regulator. J Biol Chem. 2016;291(1):1-10.

\section{Publisher's Note}

Springer Nature remains neutral with regard to jurisdictional claims in published maps and institutional affiliations. 